ISSN: 0212-5374

DOI: http://dx.doi.org/10.14201/et20153312556

\title{
HERRAMIENTAS GEOMÁTICAS UTILIZADAS EN EDUCACIÓN: SITUACIÓN ACTUAL Y SU RELACIÓN CON PROCESOS EDUCATIVOS
}

\section{Tools used about Geomatics Education: current situation and its relation to educational processes}

\section{Les outils utilisés en Éducation Géomatique: situation actuelle et sa relation avec les processus éducatifs}

José Manuel Muñoz Rodríguez*, Jorge Joo NAGATA** y José Rafael GarcíaBERMEJO GINER****

* Facultad de Educación. Universidad de Salamanca

** Facultad de Historia, Geografía y Letras. UMCE. Grupo GRIAL. Universidad de Salamanca

***** Grupo GRIAL. Universidad de Salamanca

Recibido: 20-01-2014; Aceptado: 20-04-2014; Publicado: 30-04-2015

BIBLID [0212-5374 (2015) 33, 1; 25-56]

Ref. Bibl. JOSÉ MANUEL MUÑOZ RODRÍGUEZ, JORGE JOO NAGATA y JOSÉ RAFAEL GARCÍA-BERMEJO GINER. Herramientas geomáticas utilizadas en educación: situación actual y su relación con procesos educativos. Enseñanza \& Teaching, 33, 1-2015, 25-56

RESUMEN: El objetivo del presente artículo corresponde a realizar un diagnóstico sobre las TIC geomáticas como herramientas en la enseñanza sobre el territorio, además de determinar si estas tecnologías reemplazan las características cognitivas que muestra el espacio real, cuando se utilizan desde contextos educativos particulares, estableciendo elementos, similitudes, diferencias y particularidades de la 

HERRAMIENTAS GEOMÁTICAS UTILIZADAS EN EDUCACIÓN: SITUACIÓN ACTUAL...

virtualización territorial sobre la percepción. Mediante un estudio descriptivo y correlacional, en donde el insumo básico es una encuesta aplicada a estudiantes de Chile y España en un contexto universitario, se estableció un diagnóstico sobre la utilización de herramientas TIC geomáticas y las relaciones entre las características cognitivas que muestra el espacio real y la virtualización digital de los territorios. Los resultados más relevantes de este análisis constatan que, a pesar de un uso masivo e inicial de estas herramientas, la dimensión territorial y su respectiva percepción espacial no son reemplazadas por la realidad concreta, situación que debe ser considerada en su utilización como metodología educativa.

Palabras clave: tecnologías de la información y la comunicación (TIC); geomática; territorio; educación; percepción.

SUMMARY: The aim of this article is a diagnosis about Geomatics ICT as teaching tools about the territory, and to determine whether these technologies replace cognitive characteristics showing real space, when used in educational contexts, establishing elements, similarities, differences and special features of the territorial virtualization on perception. Using a descriptive and correlational study, where the basic input is a survey of students in Chile and Spain in a university context, an analysis of the use of ICT Geomatics tools and the relations between the cognitive characteristics showing real space and the digital virtualization of the territories. The main results of this analysis show us that, despite a massive and initial use of these tools, the territorial dimension and their respective spatial perception are not replaced by the concrete reality, something that should be considered when used as an educational methodology.

Key words: information and communications technology (ICT); geomatic; territory; education; perception.

RÉSUMÉ: L'objectif de cet article est double: d'un côté, celui d'évaluer les Technologies de l'information et de la communication (TIC) géomatiques en tant qu'outils utilisés pour apprendre l'étude du territoire; et, de l'autre, celui de déterminer si ces technologies peuvent remplacer les caractéristiques cognitives de l'espace réel quand on les applique à l'enseignement dans des contextes éducatifs précis, à travers l'élucidation des éléments, des particularités, des différences et des similarités de la virtualisation territoriale par rapport à la perception. Moyennant une analyse descriptive et corrélative, dont le point de départ essentiel est une enquête faite à des étudiants provenant du Chili et de l'Espagne dans un contexte universitaire, on établira un diagnostic sur l'utilisation des outils Tic géomatiques et sur les relations existant entre les caractéristiques cognitives de l'espace réel et la virtualisation digitale des territoires. Les résultats les plus importants de cette analyse montrent que, malgré l'usage prioritaire et massif de ces outils, la dimension territoriale et sa perception spatiale ne sont pas substituées par la réalité précise, situation qui doit être considérée dans leur utilisation en tant que méthodologie éducative.

Mots clés: information et des communications (TIC); géomatique; territoire; de l'éducation; perception. 
JOSÉ MANUEL MUÑOZ RODRÍGUEZ, JORGE JOO NAGATA Y JOSÉ RAFAEL GARCÍA-BERMEJO GINER HERRAMIENTAS GEOMÁTICAS UTILIZADAS EN EDUCACIÓN: SITUACIÓN ACTUAL..

\section{INTRODUCCIÓN}

Al igual que otros fenómenos, el territorio y el espacio se han vuelto fuertemente influenciados en la actualidad por el contexto que proponen las Tecnologías de la Información y la Comunicación (TIC). Desde sus inicios como ser social, el ser humano ha estado involucrado con el espacio, siendo influido por este y a su vez generando las adaptaciones necesarias para su vida en comunidad. Para dimensionar y representar este fenómeno, se han desarrollado herramientas tecnológicas adecuadas a su momento histórico: en un comienzo fueron los mapas y el astrolabio, derivando en la actualidad en Sistemas de Información Geográfica (SIG) y Sistemas de Posicionamiento Global (GPS) en el marco del desarrollo informático y digital. Conociéndose esta dimensión como Geomática (Comes, 2002), redes sociales geolocalizadas y realidad aumentada.

La mayoría de las personas se encuentran fuertemente ligadas a la disponibilidad de tecnología, lo que se traduce en la utilización de móviles, uso intensivo de redes sociales, servicios en Red, entre otros. Sin embargo, el nivel de manejo y dominio varían, en lo que Prenski ha definido como la existencia de nativos e inmigrantes digitales (2001). Esto supone que la cantidad de herramientas, servicios y aplicaciones tecnológicas que se están utilizando se ha incrementado exponencialmente desde la consolidación de la era digital, lo que supone que la tecnología utilizada para representar y analizar la Tierra y su superficie también lo han hecho, superando la representación espacial desarrollada sólo en papel y en sus dos dimensiones.

En estos momentos, la información no es solamente digital, sino que también tiene su localización en el territorio -más allá de la localización euclidiana de estos procesos-, lo que da nuevas perspectivas de cómo entendemos la información y sus relaciones. Es por esto que en la concepción del espacio, y con ello en la derivación de muchas disciplinas, la generación de conocimiento y el desarrollo tecnológico siempre han estado fuertemente relacionados.

De manera particular, el levantamiento de datos en un contexto territorial se ha visto favorecido por la creciente capacidad de almacenamiento y procesamiento de información otorgada por los ordenadores. La información que antes se presentaba en mapas y globos terráqueos estáticos toma un fuerte poder dinamizador, pasando a lo que se entiende como la información dinámica (cartografía inteligente). Paralelo a las herramientas informáticas habituales como son los procesadores de textos, bases de datos, planillas de cálculo e Internet se encuentran otras más específicas aplicadas a la representación y el análisis del territorio (Artvinli, 2010; Buzai, 1999; Capel, 2012).

El territorio, desde la virtualidad digital, ha facilitado su conocimiento, su enseñanza y aprendizaje, y, como consecuencia, ha traído mejores condiciones en la calidad de vida de los habitantes (Freyman, 2012). Sin embargo y de manera análoga a otras interacciones sociales que se están produciendo, cabe hacerse la pregunta sobre los verdaderos roles de estas tecnologías: ¿es posible que estos 
JOSÉ MANUEL MUÑOZ RODRÍGUEZ, JORGE JOO NAGATA Y JOSÉ RAFAEL GARCÍA-BERMEJO GINER HERRAMIENTAS GEOMÁTICAS UTILIZADAS EN EDUCACIÓN: SITUACIÓN ACTUAL...

medios virtuales puedan reemplazar el espacio real, logrando obtener las mismas sensaciones y percepciones de lo que se ve y siente en la cotidianidad?

Complementado a lo anterior, se generan las siguientes interrogantes: ¿qué se entiende por TIC aplicadas a la comprensión del espacio-territorio y cuáles son las herramientas TiC que utilizan en la vida cotidiana? ¿Cuál es el estado actual sobre la conveniencia del uso de estas tecnologías en la enseñanza del espacio?

\section{OBJETIVOS E HIPÓTESIS DE TRABAJO}

El objetivo general del presente trabajo es determinar si las herramientas TIC geomáticas reemplazan las características cognitivas que muestra el espacio real, cuando se utilizan desde contextos educativos particulares, estableciendo elementos, similitudes, diferencias y particularidades de la virtualización territorial sobre la percepción. Los objetivos específicos son establecer el grado y nivel de uso de las TIC geomáticas en el proceso de entendimiento del espacio por parte de un grupo de universitarios y determinar el tipo de percepción espacial-territorial que presentan un grupo de estudiantes universitarios en base a la utilización de TIC geomáticas en su vida cotidiana. En torno a la hipótesis se plantea que la generación de datos territoriales, su análisis y visualización se han visto fortalecidos con nuevas herramientas como son las Tic geomáticas facilitando la información de los espacios en un mundo globalizado e interconectado. Sin embargo, la esencia cognitiva que ofrecen los espacios reales a nivel de las percepciones y construcciones de los sujetos no puede ser reemplazada por estos medios virtuales de información. A pesar de que la tecnología en la actualidad permite un correcto desenvolvimiento de los fenómenos que ocurren a diario en nuestra sociedad, incluido lo que pasa en el territorio, estas herramientas no logran reemplazar los reales significados que se les da a los espacios, a pesar del dominio en su uso e intensidad en su utilización ${ }^{1}$.

\section{MARCO TEÓRICO}

\subsection{Significado y representación del espacio y el territorio}

\subsubsection{El espacio representado en la tecnología}

En estos momentos nos encontramos en un contexto en que la actual tecnología permite la existencia de la hiperrealidad y de simulación en diversas dimensiones del quehacer humano, intentando representar las actividades reales de nuestras acciones en lo cotidiano (redes sociales, mapeo online, Neogeografía, por

1. En términos estadísticos la hipótesis establece que no existe correlación entre el uso y manejo de herramientas TIC respecto a las dimensiones territorialidad, afectividad y significatividadcomunicatividad. 
JOSÉ MANUEL MUÑOZ RODRÍGUEZ, JORGE JOO NAGATA Y JOSÉ RAFAEL GARCÍA-BERMEJO GINER HERRAMIENTAS GEOMÁTICAS UTILIZADAS EN EDUCACIÓN: SITUACIÓN ACTUAL..

mencionar algunas) y con ello la modificación de las coordenadas básicas en las dimensiones temporales y espaciales (Martín, Muñoz, García del Dujo y Sánchez, 2011). El espacio, como otras dimensiones, se ha visto fuertemente representado en este contexto digital, generando otros parámetros constructivos de lo constitutivo inicialmente sólo por la localización, pero que también intenta incorporar otros elementos integrantes de la fisonomía general territorial. Complementado a lo anterior, existe otro factor importante a este desarrollo de territorio virtual y que corresponde a la difusión de la información espacial, la que hoy ha alcanzado niveles muy amplios y masivos en el contexto general del avance tecnológico. La "espacialidad digital" es parte de la vida de las personas, quienes utilizan de manera constante programas como Google Earth, Mapquest, Fourthsqare, entre otros, para la consulta de lugares en diversos contextos de información como son viajes, comercio o simple conocimiento (Capel, 2009).

La dimensión espacial es especialmente apta para el uso de Internet con su generación y difusión de datos. Esta información, en un primer momento, tiene todas las condiciones para ser desarrollada a través de la Red, que se traduce en la expresión de datos tomados desde el territorio. Internet ha contribuido a difundir y popularizar los mapas hasta unos extremos antes impensables. La información territorial se hace visible, en un primer momento, mediante el desarrollo de la cartografía digital, que tiene una amplia difusión en Internet y que es la representación básica de la estructura espacial, la que puede sintetizarse en las tres dimensiones físicas concretas, llevándolas a las dimensiones topológicas que los ordenadores traducen como dato, con facilidad de difusión y replicación.

Al tener este amplio contexto de significados y usos sobre la dimensión espacial, se hacen necesarias referencias desde otras disciplinas, como la Educación, que son fundamentales para la comprensión de este concepto desde su amplio sentido. Una primera aproximación del significado espacial puede definirse como el lugar en donde se producen los acontecimientos que vivimos (García del Dujo, 2009: 105), es decir, el contexto de las existencias de las infraestructuras y de los escenarios del accionar cotidiano. Ese espacio es euclidiano, que puede ser contextualizado en coordenadas X, Y y Z, mesurable e incluso desde ciertos aspectos, replicable en diferentes formatos: mapas, vídeos, fotografías, entre otros. Pero como lo establece Garrido, en la construcción y representación que hacemos del espacio vivencial que tenemos, se genera una mayor cantidad de interacciones:

El espacio, como noción de soporte, es un concepto limitante para comprender la experiencia del hombre. Esta última no actúa sobre el espacio, sino que más bien lo configura. Todo ello es esencial para situar un contenido educativo como lo es el espacio, pues lo amplía al campo de lo cotidiano, de lo inherente, y de lo nuclear. Tal es la complejidad de este espacio, que supera todo orden estrictamente material, al mismo tiempo que no se agota en lo fijo (Garrido, 2005: 225). 
JOSÉ MANUEL MUÑOZ RODRÍGUEZ, JORGE JOO NAGATA Y JOSÉ RAFAEL GARCÍA-BERMEJO GINER HERRAMIENTAS GEOMÁTICAS UTILIZADAS EN EDUCACIÓN: SITUACIÓN ACTUAL...

Ya no existe sólo el espacio contenedor de acciones y elementos físicos, sino que también es un constructo social e incluso personal, el cual puede ser definido desde la particularidad de nuestras percepciones y complementados desde otras dimensiones como son lo temporal y lo pedagógico.

\subsubsection{Sobre el aprendizaje del espacio}

En el apartado anterior se aborda el concepto espacio más allá del simple contexto donde se sitúan las cosas. Es también donde el ser humano construye su dimensión social, con todos sus elementos implícitos, incluyendo otras dimensiones que conforman la construcción de la vida, como es el aprendizaje:

... cabe la posibilidad de pensar en unos parámetros de interconexión entre las personas y sus espacios vividos, que, tomados en conjunto, dimensionan, caracterizan y pueden reafirmarlos y reinterpretarlos educativamente y, en consecuencia, de ser manipulados; en este sentido, podríamos obtener una mejora en el propio proceso o hecho educativo en el que participan (García del Dujo y Muñoz, 2007).

De esta manera, se pueden entender dos elementos fundamentales: los espacios son elementos indisolubles de nuestra concepción universal de ser y, por ello, un elemento permanente de aprendizaje por su variabilidad, dinámica y evolución; y la realización de continuos procesos de enseñanza-aprendizaje permite la constante construcción de los sujetos, teniendo como referencia lo cotidiano como elemento referencial de sí mismo y su entorno, generando no sólo identidad, sino características de identificación que son claros referentes, constructos particulares y que evolucionan en conjunto con lo temporal. Paralelo a lo anterior, en los procesos de aprendizaje del espacio no sólo se expresan elementos referentes a lo cotidiano o a lo próximo de los sujetos: se constituye por situaciones y elementos que se encuentran en diferentes dimensiones y estructuras escalares. Es así que el punto de partida para la enseñanza y estudio del espacio tiene como referencia la experiencia personal. Los espacios personales toman la información de los entornos vividos, de las situaciones y contextos explorados en juegos y acciones; en relatos escuchados y narrados; en construcciones y abstracciones de la "realidad". Relaciones que se establecen entre características de lugares, distancias, usos y relaciones del medio. Es mediante este conocimiento espacial previamente recibido que las personas desarrollan ideas iniciales sobre el territorio y las relaciones que se dan dentro de este, dando paso a una formalización de dicha información a través de la experiencia educativa formal (Santisteban y Pagès, 2011).

Las herramientas geomáticas TIC, en una primera instancia, logran sintetizar el universo asociado con los elementos referentes al espacio, incorporando elementos que anteriormente no existían en nuestra construcción territorial: asincronía, simultaneidad y abstracción. 
JOSÉ MANUEL MUÑOZ RODRÍGUEZ, JORGE JOO NAGATA Y JOSÉ RAFAEL GARCÍA-BERMEJO GINER HERRAMIENTAS GEOMÁTICAS UTILIZADAS EN EDUCACIÓN: SITUACIÓN ACTUAL...

\subsection{Herramientas TIC geomáticas}

Como categoría de estudio y análisis, el espacio ha tenido una importante interacción entre la generación de conocimiento y el desarrollo tecnológico, particularmente esto último siempre ha estado fuertemente presente. En la actualidad, el levantamiento de datos en un contexto territorial se ha visto favorecido por la creciente capacidad de almacenamiento y procesamiento de información otorgada por los ordenadores. La información que antes se presentaba en mapas y globos terráqueos estáticos toma un fuerte poder dinamizador, pasando a lo que se entiende como la información dinámica (cartografía inteligente). Paralelas a las herramientas informáticas habituales como son los procesadores de textos, bases de datos, planillas de cálculo e Internet se encuentran otras más específicas, entre las que se pueden señalar (Artvinli, 2010; Buzai, 1999; López, 2012):

- $\quad$ Sistema de Posicionamiento Global (GPS): herramienta que permite la localización en coordenadas geográficas de cualquier punto de la superficie terrestre, mediante señales emitidas por satélites artificiales en órbita. Esta herramienta tiene múltiples aplicaciones, pero en el estudio del territorio interesa por la posibilidad de mostrar la localización de fenómenos y contextualizarlos en los mapas y planos.

- Globos terráqueos virtuales: corresponden a programas de información geográfica con imágenes de la superficie del planeta. Es posible explorar el relieve, edificios 3D y otras imágenes de la superficie del planeta (Lloret, Omtzigt, Koomen y De Blois, 2008). Dentro de este tipo de programas destaca Google Streetview, que permite la visualización de panorámicas en $360^{\circ}$ de la mayoría de las ciudades capitales del mundo, permitiendo la consulta de los usuarios, la incorporación de elementos de realidad aumentada y la posibilidad de compartir algunos contenidos (Figura 1).

- Procesamiento de imágenes satelitales: software que se utiliza para la visualización y procesamiento digital de imágenes generadas por sensores colocados en satélites artificiales.

- Sistemas de Información Geográfica (SIG): son herramientas informáticas que permiten el manejo de datos geográficamente referenciados con el fin de resolver problemas complejos presentes en el territorio (Bosque, 2012; Calvo, 2011; López, 2012).

Todas se convierten en importantes herramientas que permiten colectar, recuperar, transformar y visualizar datos sobre el mundo real (Burrough y McDonnell, 1998), situándolos en medios digitales con las ventajas que implica ese proceso. Es importante mencionar que estas herramientas agrupan, unifican e integran información. Transforman los datos disponibles de una forma que anteriormente no se tenía acceso, y colocan información antigua en un nuevo contexto (Dangermond, 2004), lo que permite mejores alcances de los datos territoriales. De esta manera se genera un sistema de soporte digital para la decisión, que integra datos referenciados espacialmente en un ambiente de respuestas a problemas 
FIGURA 1

Google Streetview en Google Earth

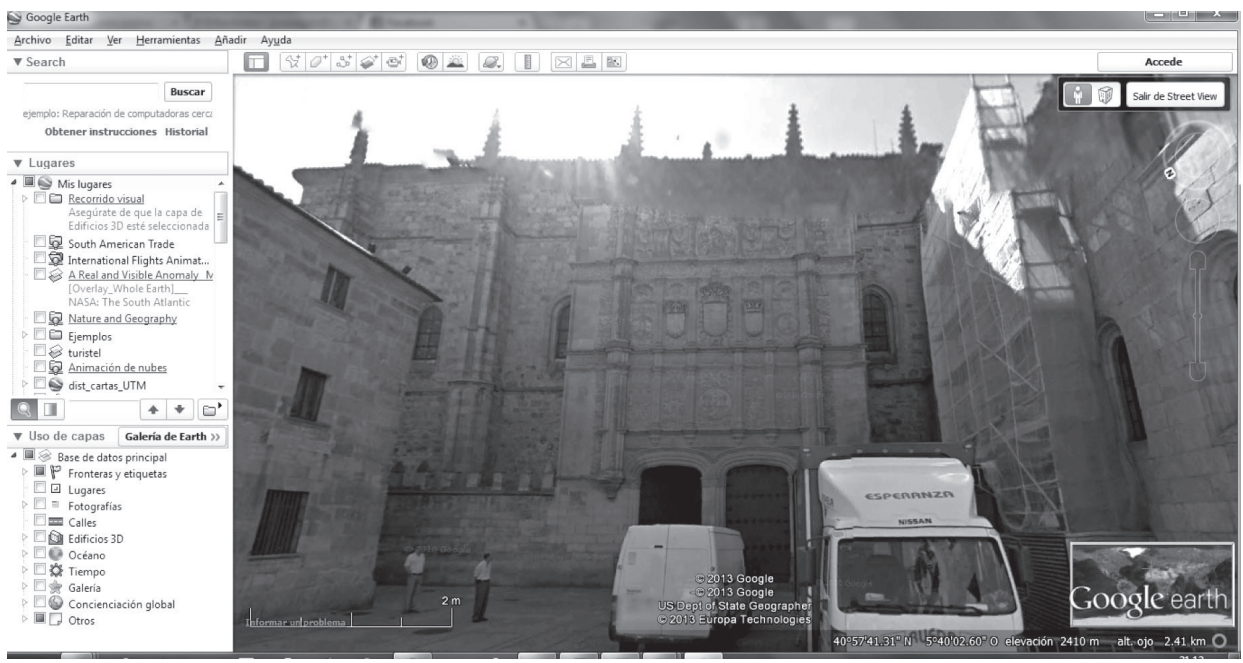

Fuente: Google (2013).

(Cowen, 1988 en Sengupta, 2007). La realidad territorial con todas sus dimensiones, que en un comienzo se define a través de modelos conceptuales asociados a la geometría euclidiana y la topología - nivel A modelos conceptuales del mundo-, se transforman en elementos discretos digitales asociados a una base de datos y a su relación con el software para hacer factible su almacenamiento y distribución -nivel B modelos de datos-. En una instancia final -nivel C representación- se logra una expresión de los datos digitales acorde al lenguaje humano mediante simplificaciones, sus atributos y relaciones o reglas, transformándose en un modelo de datos discreto como puede ser una imagen, mapa, gráfico, tabla, entre otros (Figura 2).

Los datos espaciales digitales sintetizan la realidad en términos de una serie de cualidades abstractas (Bosque, 2012):

- Su posición concreta (o posición absoluta) respecto de un sistema de coordenadas establecidas -normalmente latitud y longitud-.

- $\quad$ Sus atributos, que pueden ser temáticos o descriptivos, concretos o abstractos, siempre relacionados con el objeto y su situación en el espacio (edad, temperatura, creencia, elevación, grado académico, etc.).

- Las interrelaciones espaciales que se generan entre los objetos, en un contexto topológico que permite el traslape de las características cualitativas 


\section{FIGURA 2}

Etapas en el proceso desde la observación del mundo real hasta la creación de modelos de datos estandarizados

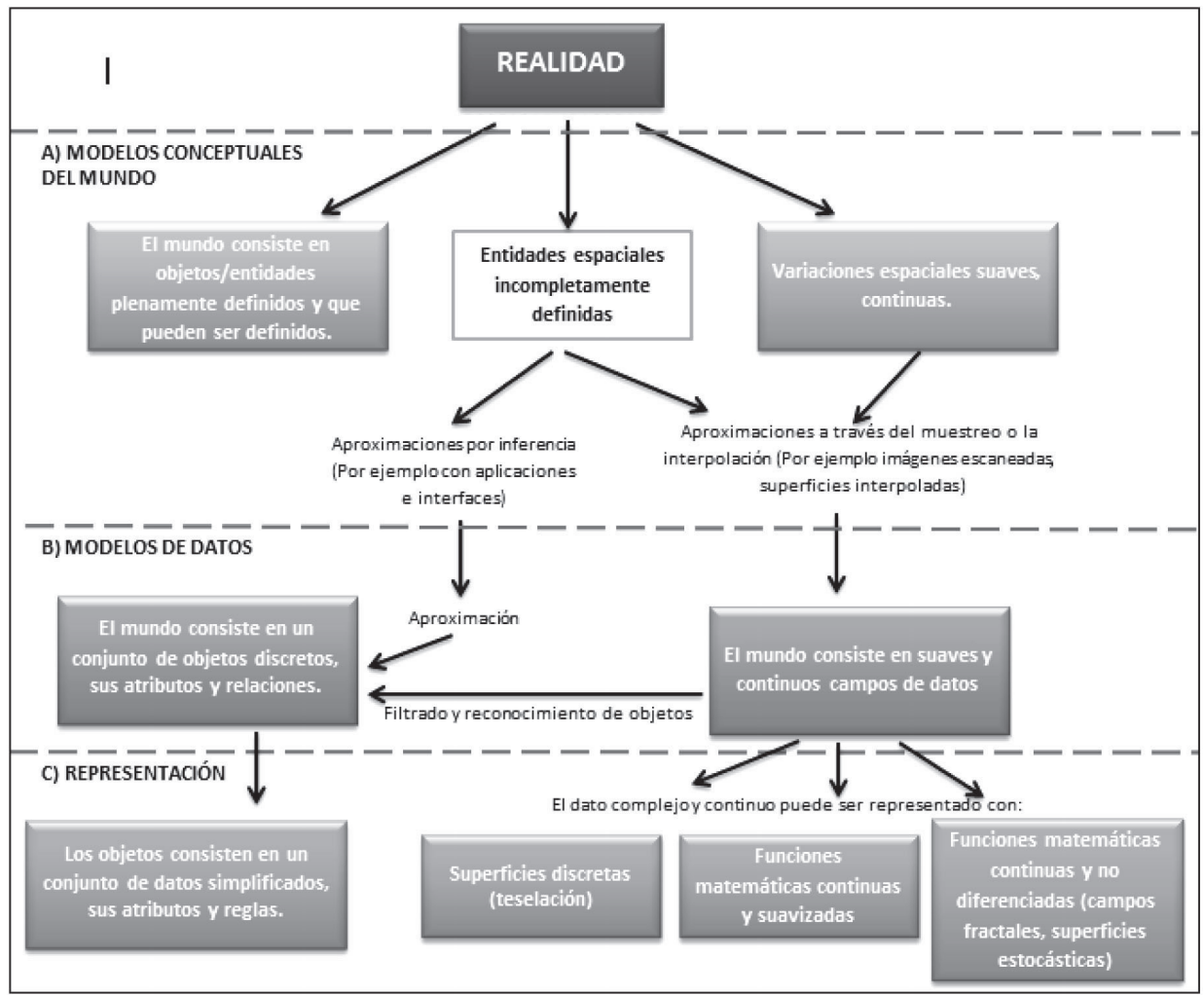

Fuente: Elaboración propia en base a Burrough et al. (1998).

en torno a las propiedades y reglas que tienen los elementos en base a sus conexiones ${ }^{2}$.

En el contexto de la Web 2.0 se ha desarrollado crecientemente lo que se conoce como Neogeografía, en donde la masificación de los mapas virtuales y el

2. Estas reglas no tienen características métricas y están referidas a la contigüidad, la conectividad, la superposición o la adyacencia de los fenómenos sobre el espacio. Esta topología no sufre variaciones en términos a su estructura de datos, siendo una de las características fundamentales en la información geomática. 

HERRAMIENTAS GEOMÁTICAS UTILIZADAS EN EDUCACIÓN: SITUACIÓN ACTUAL...

cooperativismo en la información territorial permiten la creación, procesamiento e intercambio de información geográfica (Capel, 2009; Goodchild, 2007). El concepto tiene una amplia relación con los contextos educativos ya que viene a complementar la información virtual que se desarrolla en otros tipos de herramientas (blogs, wikis, redes sociales, etc.), pero en entornos de información con características geográficas. Otra dimensión que aparece y se ve fortalecida en este contexto tecnológico educacional es la geosemántica, en donde la transferencia y estandarización de datos geográficos permite su integración, transformación y difusión en diversos niveles y escenarios, siendo el ámbito educativo uno de los más beneficiados con esta masificación tecnológica. En la geosemántica se fomenta la integración horizontal de la información territorial, además de la investigación en tiempo real mediante ambientes colaborativos de equipos multidisciplinarios (Cerda, 2008).

\subsection{Dimensión educativa de las herramientas geomáticas}

En cuanto a las competencias Tic, estas se centran en el desarrollo de habilidades y actitudes en tecnologías, articuladas a cuatro grandes competencias genéricas: comunicación, capacidad de planificar u organizar, innovación y compromiso con el aprendizaje continuo. Cada una de estas tiene sus propias características específicas, lo que permite definir aún más los objetivos a perseguir. De esta manera, las competencias que se utilizan en Geografía y las competencias TIC están altamente relacionadas (desde su estructura de desarrollo hasta sus fines), pudiendo ser integradas en el proceso de enseñanza-aprendizaje fácilmente, en un entorno adecuado a una sociedad del conocimiento (Enlaces, 2011).

Uno de los grandes beneficios de integrar herramientas geomáticas en los programas de enseñanza corresponde a la posibilidad de generar una tendencia que permita establecer procesos iniciales de investigación activa entre los estudiantes sobre el espacio, y en donde los profesores puedan desarrollar nuevas metodologías educativas usando estas herramientas en estos procesos (Jenner, 2006). El debate existente se establece en torno a qué es lo pertinente en el uso de estas metodologías: si los programas informáticos geomáticos son herramientas para la enseñanza o son un fin en sí mismos (Artvinli, 2010). En todas las dimensiones y conceptos referidos a los espacios, con diferentes niveles y dificultades, pueden ser abordados mediante las herramientas geomáticas: desde el nivel más básico - parte baja de la pirámide- en donde el estudiante es guíado por el docente en la utilización de estos programas en un contexto de una actividad de aprendizaje y que está centrado en el profesor, hasta niveles más complejos en donde los apréndices son capaces de crear su propia información sobre el territorio y que las actividades a desarrollar se centran en el estudiante (Figura 3). 
FIGURA 3

Fases de la educación en herramientas geomáticas

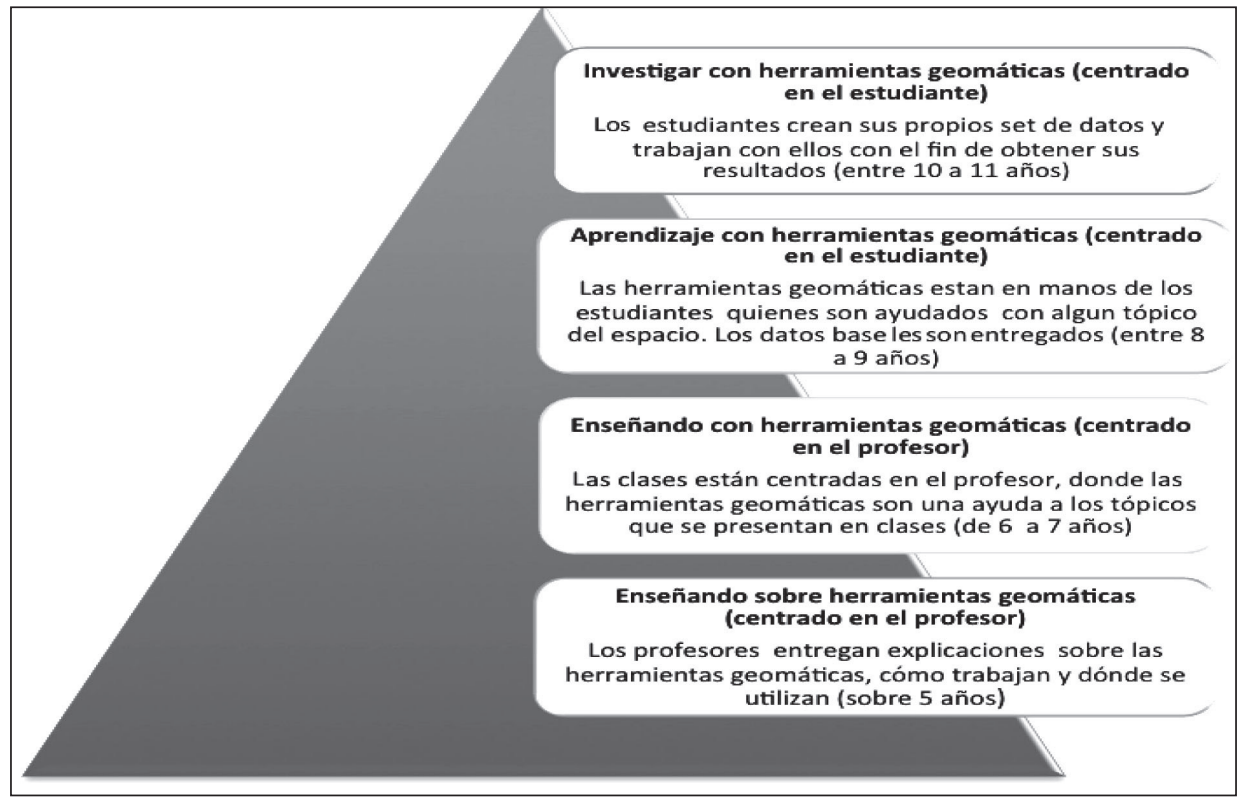

Fuente: Elaboración propia en base a Artvinli (2010).

\section{Metodología y deSARROllo de la inVESTigacióN}

Para el desarrollo de la investigación y considerando los planteamientos teóricos desarrollados, se han estructurado 4 ámbitos de acción importantes, abarcando desde la recopilación de datos hasta el análisis estadístico de estos, pasando por la consulta de fuentes secundarias y antecedentes teóricos que permitan el logro de los objetivos.

\subsection{Diseño de investigación}

El diseño de la investigación se establece en un contexto descriptivo y correlacional (Hernández, Fernández y Baptista, 2010), siendo el instrumento utilizado una encuesta aplicada a estudiantes de Chile y España en un contexto universitario. De manera general, en una primera fase se describieron los datos del muestreo y posteriormente se realizan las correlaciones entre algunas variables para comprobar la hipótesis planteada. 
JOSÉ MANUEL MUÑOZ RODRÍGUEZ, JORGE JOO NAGATA Y JOSÉ RAFAEL GARCÍA-BERMEJO GINER HERRAMIENTAS GEOMÁTICAS UTILIZADAS EN EDUCACIÓN: SITUACIÓN ACTUAL...

\subsection{Variables e instrumento}

\subsubsection{Variables}

En una primera fase y en base a los objetivos e hipótesis planteadas, se han definido 6 dimensiones que pretenden ser medidas y relacionadas para el cumplimiento de los objetivos planteados, mediante el desarrollo de un instrumento de recopilación (ver anexo encuesta). Dichas dimensiones son características sociopersonales, uso de herramientas TIC, dimensión geomática, dimensión territorial, dimensión afectividad y dimensión significancia-comunicabilidad.

\subsubsection{Diseño del instrumento}

La encuesta realizada cuenta con un total de 40 ítems, de los cuales 11 corresponden a preguntas sobre las características del encuestado (género, edad, país, software, grado de utilización de TIC, entre otros). En los 29 ítems siguientes se establecieron afirmaciones en donde se agrupaba cada dimensión explicada en el ítem anterior, siendo operativa a través de una medición en escala de tipo Likert consistente en un conjunto de ítems presentados de forma de afirmaciones, ante lo cual se pide la evaluación de los encuestados (Hernández et al., 2010: 245). De esta manera, en cada ítem los valores oscilaban de 1 -en total desacuerdo- a 5 -muy de acuerdo-. En una primera instancia la encuesta fue evaluada por expertos, quienes establecieron la validez teórica de los ítems consultados. Por otro lado, los análisis de fiabilidad del instrumento revelan un coeficiente de Alfa de Cronbach de 0,84 cuyo valor se adecúa a este tipo de estudios.

\subsection{Población y muestra}

La población establecida para el estudio está compuesta por estudiantes de la Universidad de Salamanca -USAL-, España (grado de Pedagogía) y la Universidad Metropolitana de Ciencias de la Educación -umCE- de Chile (grado de profesor en Historia y Geografía), contabilizando un total de 168 registros. Se eligieron dichos grados ya que la formación que reciben se contextualiza con la significación de los espacios y territorios como proceso educativo (Departamento de Historia y Geografía y uMCE, 2009; Muñoz, 2013). Además, al ser estudiantes jóvenes, la utilización constante de tecnología en su vida cotidiana permite evidenciar un mayor uso de estas herramientas en los procesos personales y sociales en que se desenvuelven (IAB Spain, 2013; Prensky, 2001; vTR, Adimark y Educar Chile, 2008).

\subsection{Análisis de datos}

Luego de obtenidos los datos del muestro, se procedió al procesamiento de los datos obtenidos a través del formulario ingresando y codificando los valores al 
JOSÉ MANUEL MUÑOZ RODRÍGUEZ, JORGE JOO NAGATA Y JOSÉ RAFAEL GARCÍA-BERMEJO GINER HERRAMIENTAS GEOMÁTICAS UTILIZADAS EN EDUCACIÓN: SITUACIÓN ACTUAL...

programa IBM SPSS 20. Los principales análisis estadísticos en base a las dimensiones consultadas que se realizaron con el programa son los siguientes:

- Estadísticos descriptivos.

- Correlaciones.

- Comparación de medias.

Los resultados obtenidos fueron interpretados y analizados en el contexto de la investigación realizada, estableciendo las características y relaciones respectivas en base al muestreo realizado.

\section{PRESENTACIÓN DE LOS DATOS Y Discusión DE RESUltados}

Se presentan los resultados más relevantes en torno a los datos y los valores que se obtuvieron en la encuesta:

\subsection{Características sociopersonales de la muestra}

En esta primera sección se presentan los elementos esenciales de la muestra, con las caracterizaciones generales en torno a género, edad, uso de tecnología y herramientas geomáticas de los estudiantes consultados. Desde el contexto geográfico de los encuestados, dentro de los 168 registros válidos obtenidos, el 69,6\% corresponden a Chile como país y el 30,4\% a España, siendo de manera particular las ciudades de origen de los estudiantes Santiago, Salamanca, Talagante y Ciudad Rodrigo. De manera particular en los otros campos los resultados son los siguientes:

- Género: la mayor parte de la muestra, con un 55\% aproximado, está compuesta por estudiantes del sexo femenino, mientras el $45 \%$ corresponde a estudiantes del sexo masculino (Figura 4). Lo anterior se relaciona con algunos reportes que establecen que las estudiantes mujeres tienen una mayor preferencia por las carreras relacionadas con el ámbito de la educación y la formación (Mizala, 2011; Pérez, 2003).

- Edad: las edades presentes en la muestra fluctúan entre los 17 y 42 años con un promedio de 21,39 años. Son dominantes los estudiantes de 19 años (moda $=19$ con una frecuencia de 42 registros). Lo anterior se explica por el nivel en que fue realizada la muestra, coincidente en el $2 .^{\circ}$ año de Pedagogía (Figura 5). 
38 JOSÉ MANUEL MUÑOZ RODRÍGUEZ, JORGE JOO NAGATA Y JOSÉ RAFAEL GARCÍA-BERMEJO GINER HERRAMIENTAS GEOMÁTICAS UTILIZADAS EN EDUCACIÓN: SITUACIÓN ACTUAL...

FIGURA 4

Distribución por género

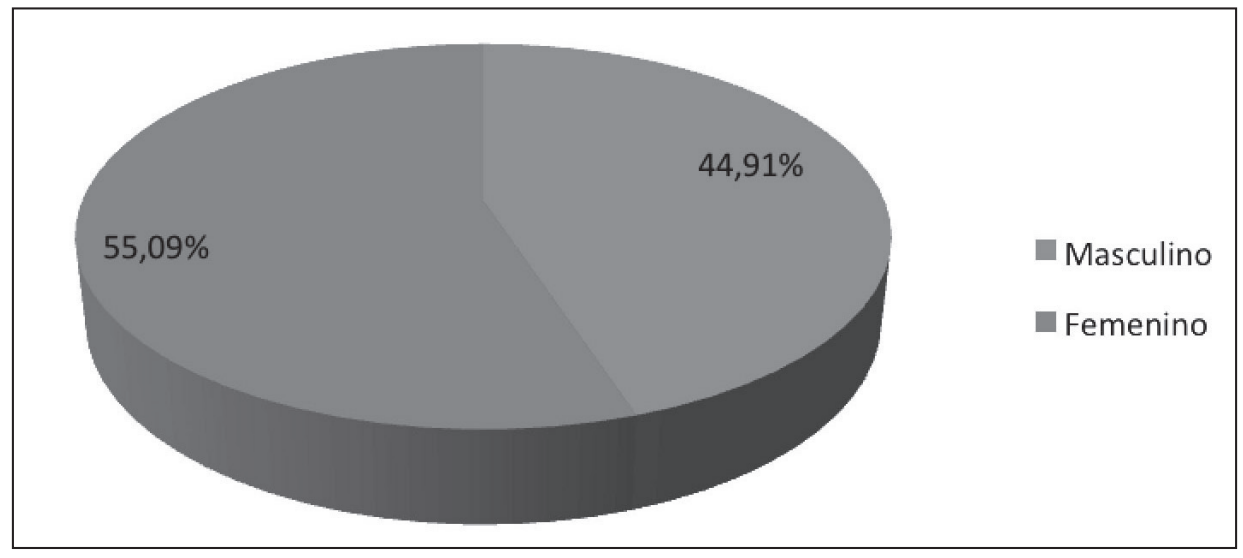

Fuente: Elaboración propia.

FIGURA 5

Distribución de edades de la muestra $(\mathrm{n}=168)$

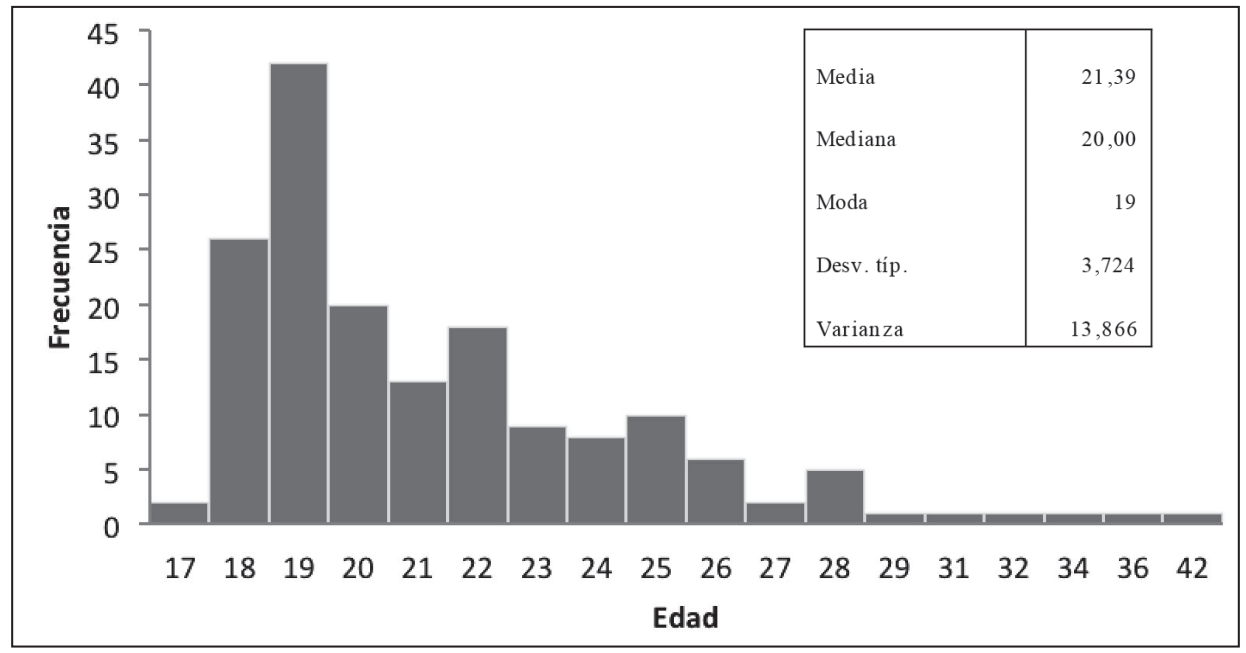

Fuente: Elaboración propia. 
JOSÉ MANUEL MUÑOZ RODRÍGUEZ, JORGE JOO NAGATA Y JOSÉ RAFAEL GARCÍA-BERMEJO GINER HERRAMIENTAS GEOMÁTICAS UTILIZADAS EN EDUCACIÓN: SITUACIÓN ACTUAL...

\subsection{Uso de herramientas TIC y geomáticas}

Desde las consultas realizadas en la encuesta, referidas a la dimensión tecnológica de los usuarios, se presentan los siguientes resultados:

- Tiempo dedicado al uso de herramientas TIC: Se puede observar que hay un uso intensivo por parte de los estudiantes de la tecnología móvil, que se traduce en mayor tiempo dedicado a la semana (Figura 6). Además las aplicaciones de la Web 2.0 y los tiempos de conexión han aumentado debido a las características propias de los programas que se utilizan (redes sociales, mensajería instantánea, correo electrónico, juegos, entre otros), necesitando una mayor inversión de tiempo, la cual debe ser realizada de manera constante y, en algunos casos, de manera continua (IAB Spain, 2013; VTR et al., 2008). Lo anterior también se relacionaría con la cantidad y tipo de aparatos electrónicos que se poseen (Figura 7), la complejidad tecnológica que tienen estas herramientas y la posibilidad de conectividad que se tiene con estos dispositivos.

- Dispositivo utilizado: Como se puede observar en los datos, los encuestados utilizan varios dispositivos dentro su equipamiento tecnológico permanente (Figura 7). De manera paralela, existe un predominio de aparatos que permiten la movilidad de los estudiantes, logrando superar las barreras espaciales que en un inicio se generaban en el uso de estas herramientas. La tendencia general -y que se mantiene en incremento- establece el predominio de dispositivos que sean portátiles y que puedan ser utilizados en tiempo real, permitiendo generar aplicaciones que se adapten mejor a la necesidad de los usuarios. De esta manera, los dispositivos fijos y de gran volumen comienzan a desaparecer de los requerimientos de los usuarios actuales (Contreras, 2013), dando paso a la portabilidad y la posibilidad de reunir en un único aparato funciones que antes eran independientes (cámara de fotografía, vídeo, grabadora, GPS, agenda, por mencionar algunos), permitiendo la interoperabilidad de estas funciones y las redes presentes en la Web 2.0, con el debido intercambio de datos generados por el usuario a través de estos dispositivos. 
40 JOSÉ MANUEL MUÑOZ RODRÍGUEZ, JORGE JOO NAGATA Y JOSÉ RAFAEL GARCÍA-BERMEJO GINER HERRAMIENTAS GEOMÁTICAS UTILIZADAS EN EDUCACIÓN: SITUACIÓN ACTUAL...

FIGURA 6

Tiempo dedicado al uso del ordenador en la semana $(n=168)$

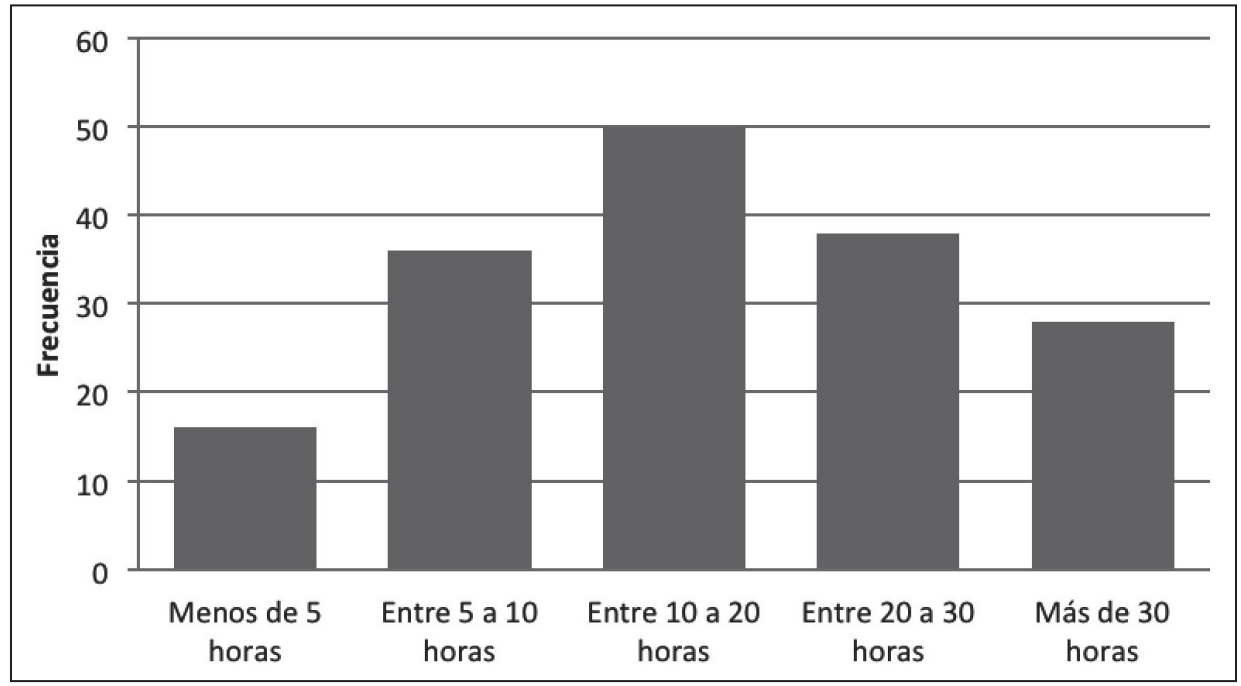

Fuente: Elaboración propia.

\section{FIGURA 7}

Tipo de dispositivo utilizado $(\mathrm{n}=168)$

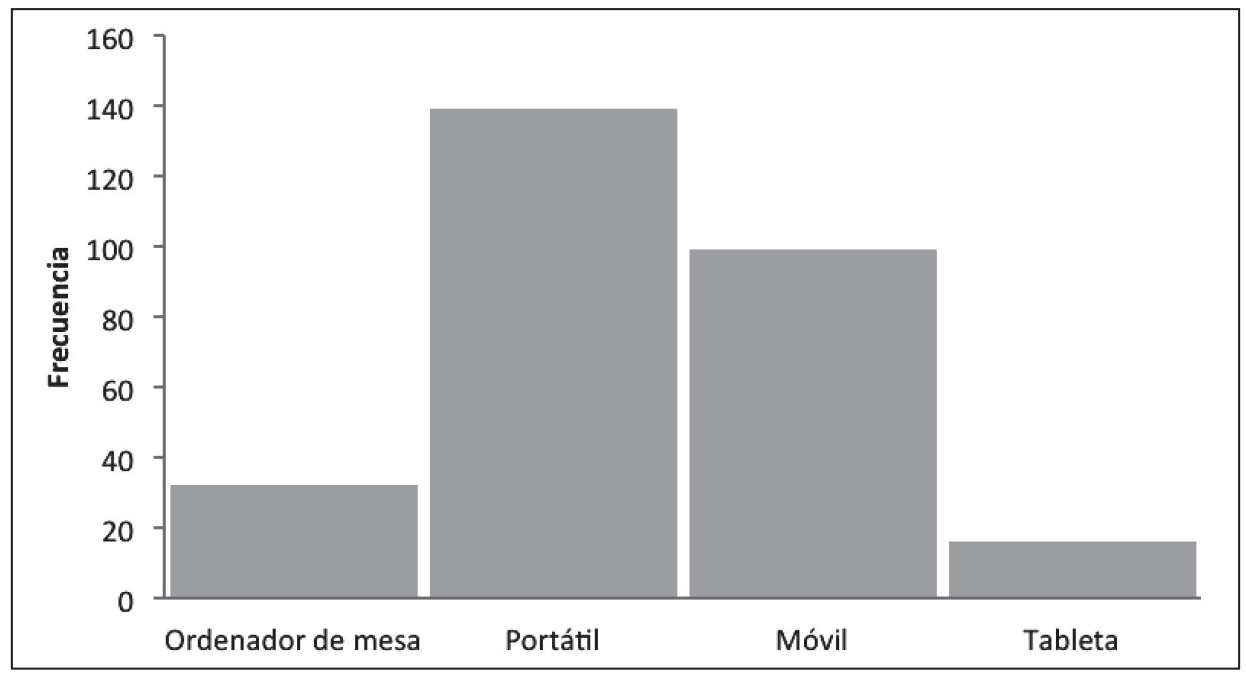

Fuente: Elaboración propia. 
JOSÉ MANUEL MUÑOZ RODRÍGUEZ, JORGE JOO NAGATA Y JOSÉ RAFAEL GARCÍA-BERMEJO GINER HERRAMIENTAS GEOMÁTICAS UTILIZADAS EN EDUCACIÓN: SITUACIÓN ACTUAL...

- $\quad$ Nivel de uso en TIC: Mientras que en un contexto de herramientas generales TIC la mayoría de los encuestados expresaba su dominio a nivel medio, la situación cambiaba cuando se consultaba sobre el dominio de las herramientas TIC geomáticas (Figura 8). La utilización de estas herramientas geomáticas se encuentra en un proceso inicial de masificación, respecto a otras herramientas presentes en la Web 2.0, a pesar de que su desarrollo desde sus origenes ha ido a la par con el crecimiento informático.

FIGURA 8

Nivel en el uso de TIC versus el nivel de uso de herramientas geomáticas

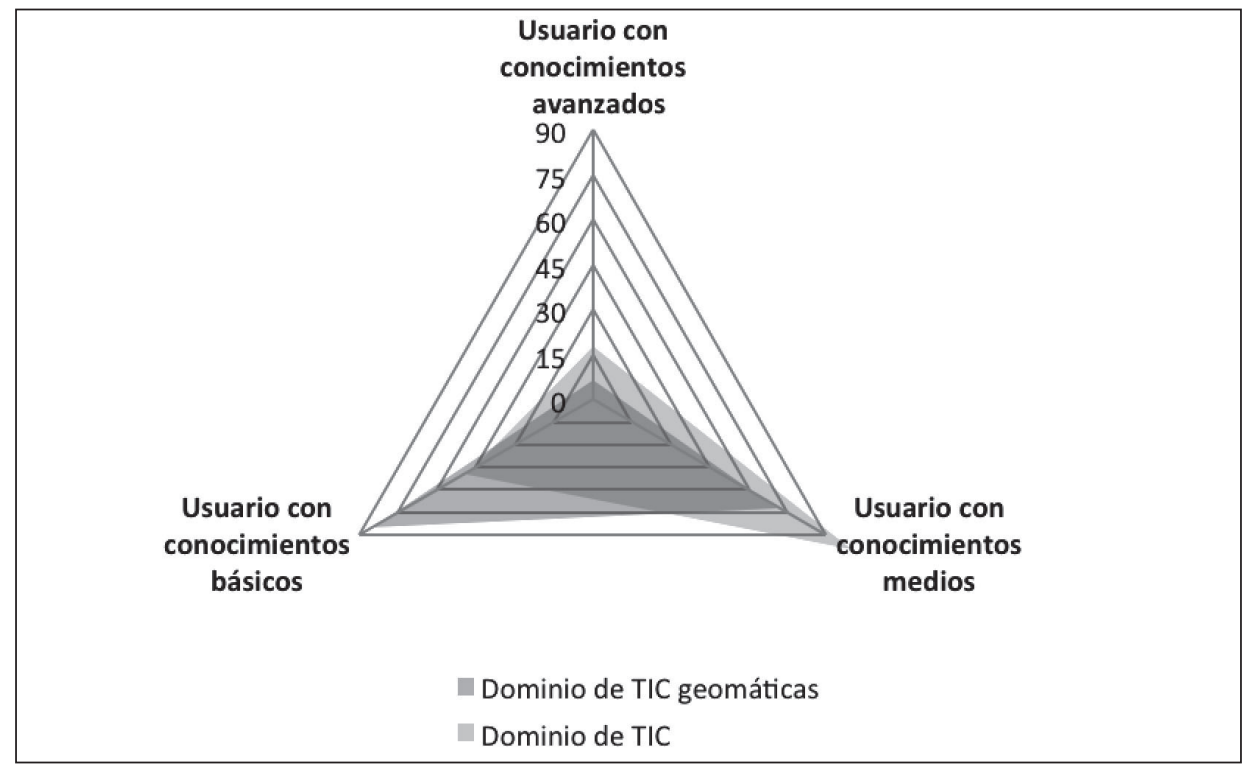

Fuente: Elaboración propia.

En la actualidad, estas aplicaciones han captado los requerimientos del usuario común permitiendo generar contenidos, almacenarlos y sociabilizarlos iniciando una nueva etapa en la utilización de estas herramientas, en donde la interactividad y espacialidad pasan a incorporar las características propias de las redes sociales (López, 2012) de manera automática sin que el usuario requiera de conocimientos y competencias en el uso de estas herramientas.

En este diagnóstico (Figura 9) es posible establecer que la percepción en torno a las herramientas geomáticas se condice con la de programa de búsqueda y consulta de información territorial, otorgando datos concretos de la superficie terrestre dentro de un modelo de representación. Sin embargo, estas herramientas 
JOSÉ MANUEL MUÑOZ RODRÍGUEZ, JORGE JOO NAGATA Y JOSÉ RAFAEL GARCÍA-BERMEJO GINER HERRAMIENTAS GEOMÁTICAS UTILIZADAS EN EDUCACIÓN: SITUACIÓN ACTUAL..

no presentan las mismas dinámicas que se presentan en las redes sociales en torno a la creación y difusión de la información.

\section{FIGURA 9}

Nivel en el uso de herramientas geomáticas (dimensión geomática)

19.- Estas herramientas me
ayudan a profundizar el
conocimiento sobre los lugares
que consulto.
$\begin{gathered}\text { 11.- Para buscar una dirección } \\ \text { selecciono y proceso }\end{gathered}$ $\begin{aligned} & \text { Media } \\ & \text { Mediana } \\ & \text { Desv. típ. }\end{aligned}$

Fuente: Elaboración propia.

- Tipo de berramienta geomática utilizada: En la actualidad existen una serie de herramientas geomáticas que se utilizan en contextos de redes sociales, generación y difusión de datos territoriales. También existen visualizadores del territorio que se encuentran al alcance de cualquier usuario, sin la necesidad de tener competencias particulares para su utilización. En su mayoría dichos programas estan asociados a grandes plataformas de software y compañías proveedoras de servicios de información. De esta manera, los resultados de la encuesta (Figura 10) establecen que la empresa Google con sus plataformas Maps y Streetview mantiene una alta demanda de sus servicios, lo que se explicaría por su facilidad de uso, funcionamiento en el contexto de otras aplicaciones y la actualización constante de su estructura de datos espaciales digitales (IDEE, 2010). También es importante mencionar que los requerimientos técnicos para el funcionamiento del software de la compañía Google no son necesariamente relevantes a la hora de utilizar este tipo de programas, a diferencia de otras plataformas como Foursquare, que mantiene restricciones a teléfonos móviles y tabletas inteligentes de 
gama alta. Lo anterior se replica en la muestra obtenida con la preferencia de los estudiantes encuestados.

FIGURA 10

Tipo de herramienta geomática más utilizada

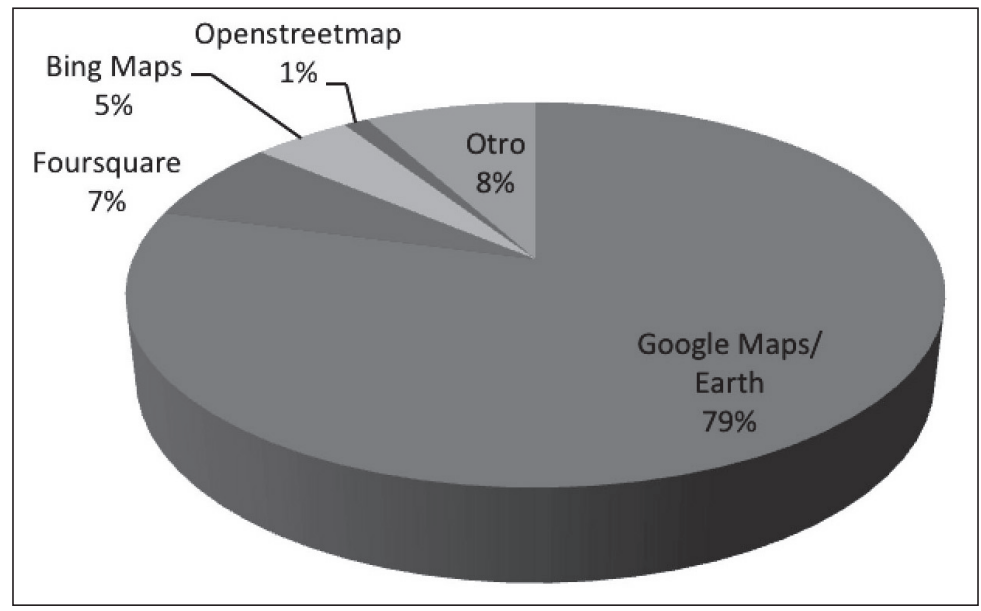

Fuente: Elaboración propia.

\subsection{Resultados de las dimensiones espaciales}

Las dimensiones espaciales Territorialidad, Afectividad y Significatividad-Comunicabilidad son las que representan la percepción de los encuestados en torno a su construcción de espacios mediante las herramientas geomáticas. Se dimensionaron las percepciones del grupo de universitarios, teniendo los resultados que se dan a continuación:

- Dimensión Territorial: Los valores generales obtenidos -todos sobre 3 en la escala- establecen que las representaciones gráficas digitales de estos programas y su construcción física concreta sobre los espacios responden a los requerimientos que se tienen sobre información sobre el territorio que tienen los usuarios consultados (Figura 11). Las interfaces gráficas de utilización y la información desplegada por este tipo de software se relacionan con las necesidades de datos espaciales por parte de los consultados y, de la misma manera, su utilización y manejo no revisten mayor complejidad para el usuario de cualquier nivel tecnológico.

Las medidas de tendencia central complementan el análisis, obteniendo valores superiores a los valores neutrales (en la escala Likert aplicada a valores $=3$, línea de color rojo), tendiendo a "de acuerdo" o "muy de acuerdo". Los encuestados perciben que la información sobre el territorio -que puede ser concreta o abstracta, visible o invisible- y que entregan estos programas responde adecuadamente 
a los requerimientos sobre este tipo de datos. De la misma manera generar y difundir este tipo de información se realiza con facilidad, permitiendo una mayor interacción entre datos, entre programas o plataformas y entre usuarios a través de las redes sociales.

FIGURA 11

Dimensión territorial

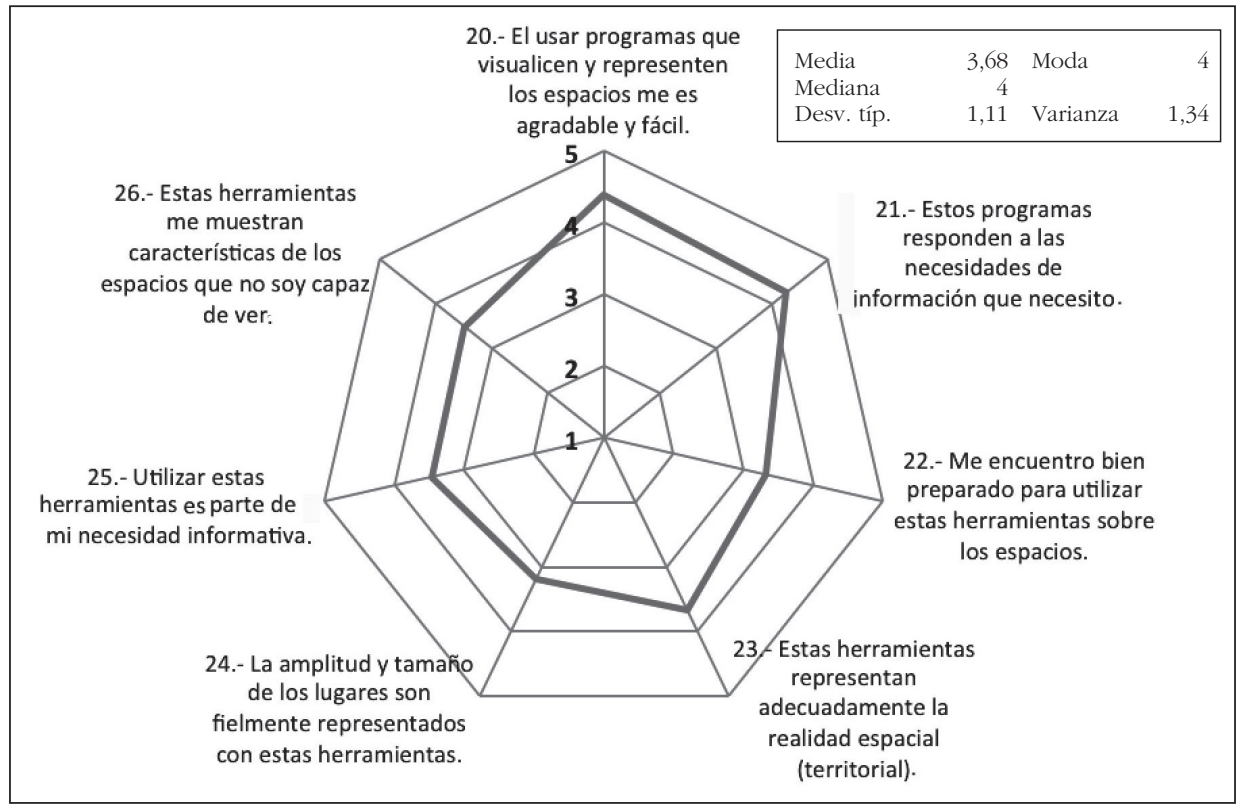

Fuente: Elaboración propia.

Destaca la positiva percepción en torno al manejo de estos territorios virtuales generados por ordenador -particularmente en torno a su representación y visualización- y que responde a la estructura de diseño que tiene este tipo de software, con comandos sencillos e intuitivos para el usuario, en donde la imagen del espacio tiene un predominio importante en la interactividad que se realiza, lo que facilitaría su utilización (Royo, 2004). Así, en esta dimensión, y debido al manejo de los datos y cómo estos se representan, existiría una presencia inicial de territorialidad creada por las herramientas geomáticas permitiendo que los encuestados establezcan grados de identificación sobre el espacio.

- Dimensión Afectividad: Por contraposición a la dimensión Territorial, la dimensión Afectividad mantiene valores iguales o inferiores a 3 en sus medidas de tendencia central (Figura 12). Las afirmaciones planteadas en esta dimensión se 
establecen desde el plano emotivo-perceptual de los encuestados, estableciéndose que no existe una mayor representatividad territorial por parte de estos programas. En una primera aproximación, el sentimiento de presencialidad en torno a los territorios puede ser desarrollado por estos programas. Sin embargo, la esencia en torno a los sentimientos y referencias personales no es posible de sustituir, lográndose sólo una aproximación inicial y básica al concepto real de espacio. Otro elemento importante a destacar es que estas herramientas no son parte constitutiva de la vida de los encuestados, pudiéndose establecer que son herramientas auxiliares que pueden ser obviadas en su uso.

FIGURA 12

Dimensión afectividad

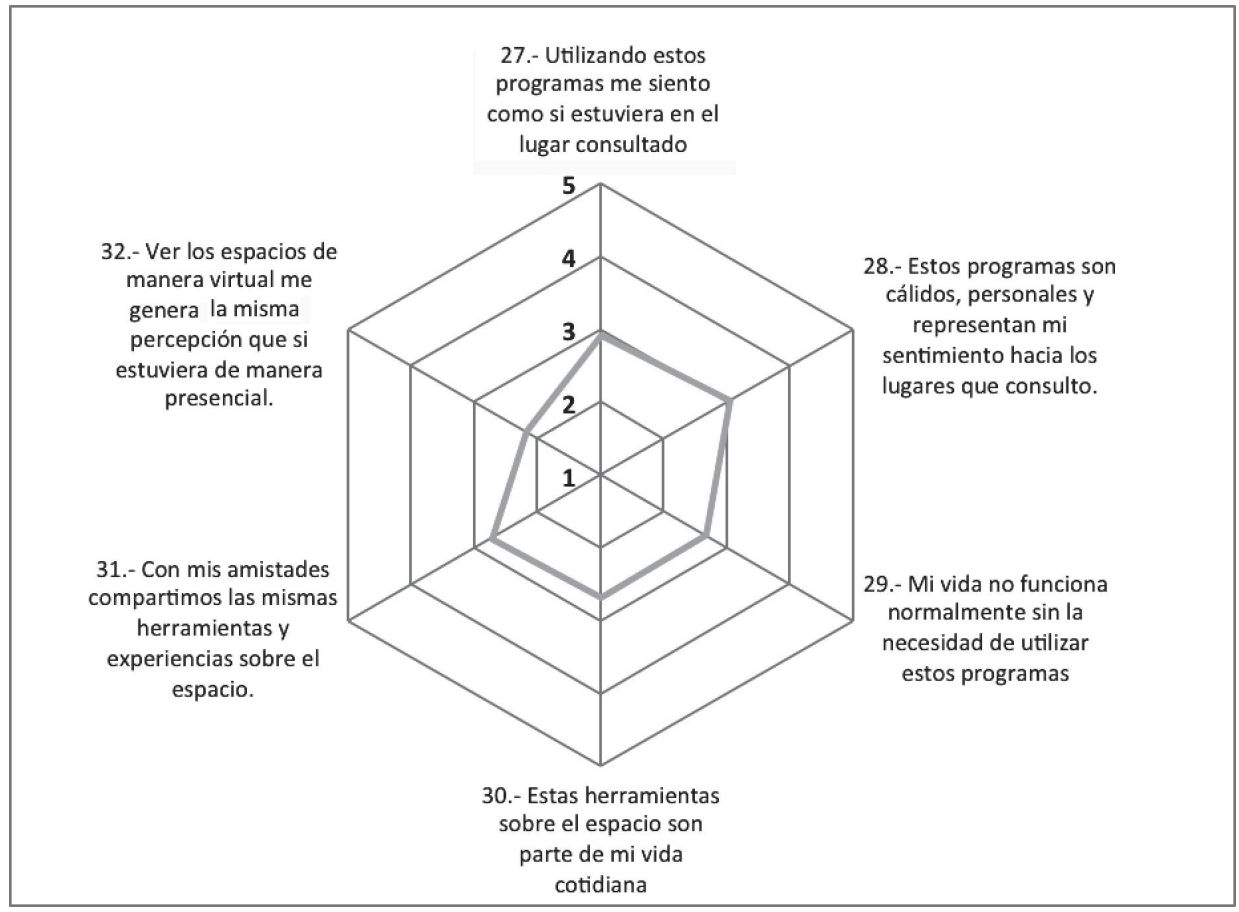

Fuente: Elaboración propia.

- Dimensión Significatividad-Comunicabilidad: Es el aspecto que tiene una mayor variabilidad relativa en los datos obtenidos (Figura 13) y las particularidades de los resultados están dadas en los ítems de la comunicabilidad de información, en los cuales los encuestados establecen que es posible compartir la información que se está consultando sobre el espacio. Lo anterior se 
explicaría por el contexto en que se realiza la utilización de las herramientas geomáticas: son programas que permiten la visualización de datos digitales sobre el territorio, por lo que los elementos de información concreta pueden ser replicados y distribuidos.

FIGURA 13

Dimensión significatividad-comunicabilidad

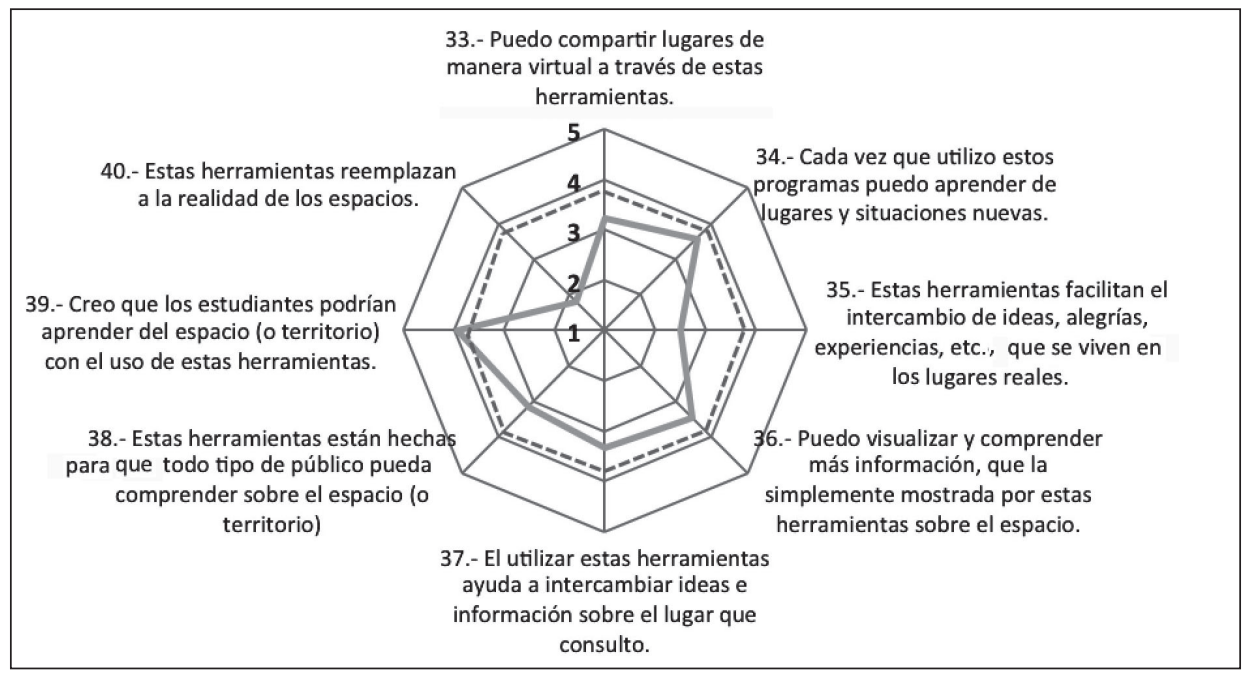

Fuente: Elaboración propia.

Sin embargo, en las preguntas referentes a la significatividad de los lugares las respuestas obtenidas establecen que no existe un reemplazo de estas herramientas sobre la realidad, ya que, al representar datos concretos, los aspectos intangibles e invisibles del territorio, los cuales no se pueden cuantificar y almacenar, quedan omitidos para este tipo de programas. Las herramientas geomáticas no estarían reemplazando la realidad presente en los espacios, en donde la opción «muy en desacuerdo" representa al 77,4\% de los encuestados, permitiendo establecer que la mayoría de los encuestados no ven todos los elementos existentes en el territorio a través de este tipo de software.

\subsection{Correlaciones entre las dimensiones}

Al considerar las relaciones que tienen las tres dimensiones propuestas, se observa que todas tienen algún grado de correlación significativo, siendo la única afirmación que queda descartada la n. ${ }^{\circ} 11$ (para buscar una dirección o localización: busco, selecciono y proceso información a través del uso de herramientas TIC), 

HERRAMIENTAS GEOMÁTICAS UTILIZADAS EN EDUCACIÓN: SITUACIÓN ACTUAL...

lo cual podría ser explicado por lo genérico de la afirmación y la amplia gama de herramientas Tic existente que no sólo abarcan el mercado de los programas geomáticos. Esto establece que cada dimensión es parte importante del conjunto, transformándose en una unidad en el entendimiento y representación que se realiza sobre el territorio a través de las herramientas geomáticas.

TABLA 1

Correlaciones de las dimensiones espaciales

\begin{tabular}{|c|c|c|c|c|}
\hline & & $\begin{array}{c}\text { DIMENSIÓN } \\
\text { TERRITORIALIDAD }\end{array}$ & $\begin{array}{l}\text { DIMENSIÓN } \\
\text { AFECTIVIDAD }\end{array}$ & $\begin{array}{c}\text { DIMENSIÓN } \\
\text { SIGNIFICATIVIDAD- } \\
\text { COMUNICABILIDAD }\end{array}$ \\
\hline \multirow{3}{*}{$\begin{array}{c}\text { DIMENSIÓN } \\
\text { TERRITORIALIDAD }\end{array}$} & $\begin{array}{l}\text { Correlación de } \\
\text { Pearson }\end{array}$ & 1 &, $523^{* *}$ &, $494^{* * *}$ \\
\hline & Sig. (bilateral) & & ,000 & 000 \\
\hline & $\mathrm{N}$ & 168 & 168 & 168 \\
\hline \multirow{3}{*}{$\begin{array}{c}\text { DIMENSIÓN } \\
\text { AFECTIVIDAD }\end{array}$} & $\begin{array}{c}\text { Correlación de } \\
\text { Pearson }\end{array}$ &, $523^{* *}$ & 1 &, $604^{* * *}$ \\
\hline & Sig. (bilateral) &, 000 & & 000 \\
\hline & $\mathrm{N}$ & 168 & 168 & 168 \\
\hline \multirow{3}{*}{$\begin{array}{c}\text { DIMENSIÓN } \\
\text { SIGNIFICATIVIDAD- } \\
\text { COMUNICABILIDAD }\end{array}$} & $\begin{array}{c}\text { Correlación de } \\
\text { Pearson }\end{array}$ &, $494^{* *}$ &, $604^{* *}$ & 1 \\
\hline & Sig. (bilateral) &, 000 &, 000 & \\
\hline & $\mathrm{N}$ & 168 & 168 & 168 \\
\hline
\end{tabular}

${ }^{* *}$ La correlación es significativa al nivel 0,01 (bilateral). Fuente: Elaboración propia.

La mayor relación se establece entre las dimensiones Afectividad versus Significatividad-Comunicabilidad $(\mathrm{r}=0$,604). La expresión -comunicación- de lo que percibimos del territorio y los significados que damos a los lugares están cargados con vínculos afectivos de diferentes grados. Dichos lazos difieren en intensidad, sutileza y modo de expresión que tienen las personas, y que, en casos extremos, pueden derivar en elementos de topofilia o topofobia (Tuan, 2007: 130).

En cuanto el uso y experticia en TIC, dichas preguntas se correlacionaron con las dimensiones espaciales consultadas, obteniendo los siguientes resultados (Tabla 2): 
JOSÉ MANUEL MUÑOZ RODRÍGUEZ, JORGE JOO NAGATA Y JOSÉ RAFAEL GARCÍA-BERMEJO GINER HERRAMIENTAS GEOMÁTICAS UTILIZADAS EN EDUCACIÓN: SITUACIÓN ACTUAL..

TABLA 2

Correlaciones entre uso y experticia TIC vs dimensiones espaciales $(n=168)$

\begin{tabular}{|c|c|c|c|c|c|}
\hline & \multicolumn{4}{|c|}{$\mathrm{r}$} \\
\hline & & $\begin{array}{l}\text { DiMENSIÓN } \\
\text { GEOMÁTICA }\end{array}$ & $\begin{array}{l}\text { DIMENSIÓN } \\
\text { TERRITORIAL }\end{array}$ & $\begin{array}{l}\text { DIMENSIÓN } \\
\text { AFECTIVIDAD }\end{array}$ & $\begin{array}{c}\text { DIMENSIÓN } \\
\text { SiGNIFICANCIA- } \\
\text { COMUNICABILIDAD } \\
\end{array}$ \\
\hline \multirow{7}{*}{ 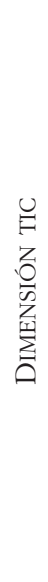 } & $\begin{array}{l}\text { ¿Cuánto tiempo dedica } \\
\text { al uso de ordenador a } \\
\text { la semana? }\end{array}$ & 0,365 & 0,320 & 0,430 & 0,526 \\
\hline & $\begin{array}{l}\text { Uso de ordenador de } \\
\text { mesa }\end{array}$ & 0,291 & 0,330 & 0,254 & 0,353 \\
\hline & Uso de portátil & 0,368 & 0,350 & 0,372 & 0,453 \\
\hline & Uso de móvil & 0,334 & 0,327 & 0,289 & 0,305 \\
\hline & Uso de tableta & 0,428 & 0,416 & 0,430 & 0,367 \\
\hline & $\begin{array}{l}\text { Según su percepción } \\
\text { ¿en qué nivel se } \\
\text { categoriza en el uso } \\
\text { de TIC? }\end{array}$ & 0,463 & 0,454 & 0,416 & 0,414 \\
\hline & $\begin{array}{l}\text { ¿Cuál es el nivel de } \\
\text { manejo de herramientas } \\
\text { Geomáticas? }\end{array}$ & 0,487 & 0,549 & 0,444 & 0,495 \\
\hline
\end{tabular}

Fuente: Elaboración propia.

En este caso las variables se encuentran levemente correlacionadas, pero no son significativas para entender un real reemplazo de las dimensiones territoriales mediante medios tecnológicos $(\mathrm{r}>0,32)$. Destacan el uso de ordenador de mesa, que presenta los valores menores $(r>0,291)$ y que puede ser explicado por ser una herramienta que va en retirada en los usos en TIC. Sin embargo, el uso de dispositivos móviles, como son los teléfonos smartphone y las tabletas, tampoco representa valores significativos $(r>0,289)$. En torno a la relación que existe en el uso de herramientas TIC y geomáticas respecto a las dimensiones espaciales, los valores aumentan, aunque no significativamente $(\mathrm{r}>0,4)$, lo cual podría ser explicado, en un inicio, por los elementos concretos que se establecen en los espacios y la posible replicabilidad como dato mediante estos programas. Lo anterior permite su facilidad de creación como información territorial, su almacenamiento y consecuente distribución mediante las redes sociales existentes.

Cuando se analizan directamente las dimensiones consultadas, los resultados establecen que existe una correlación media entre el entendimiento y uso de las herramientas geomáticas y cada una de las definiciones representativas de la espacialidad ( $r>0,413)$, lo que da indicios de que existe algún grado de percepción equivalente mediante el uso de TIC asociadas al territorio (Tabla 3). 
JOSÉ MANUEL MUÑOZ RODRÍGUEZ, JORGE JOO NAGATA Y JOSÉ RAFAEL GARCÍA-BERMEJO GINER HERRAMIENTAS GEOMÁTICAS UTILIZADAS EN EDUCACIÓN: SITUACIÓN ACTUAL...

TABLA 3

Correlaciones dimensión Geomática vs dimensiones espaciales $(n=168)$

\begin{tabular}{|c|c|c|c|c|}
\hline \multicolumn{2}{|c|}{} & $\begin{array}{c}\text { DimENSIÓN } \\
\text { TERRITORIALIDAD }\end{array}$ & $\begin{array}{c}\text { DIMENSIÓN } \\
\text { AFECTIVIDAD }\end{array}$ & $\begin{array}{c}\text { DiMENSIÓN } \\
\text { SIGNIFICATIVIDAD- } \\
\text { COMUNICABILIDAD }\end{array}$ \\
\hline \multirow{2}{*}{$\begin{array}{c}\text { DIMENSIÓN } \\
\text { GEOMÁtICA }\end{array}$} & $\begin{array}{c}\text { Correlación de } \\
\text { Pearson }\end{array}$ &, $564^{* *}$ &, $469^{* * *}$ &, $413^{* *}$ \\
\cline { 2 - 5 } & Sig. (bilateral) &, 000 &, 000 &, 000 \\
\cline { 2 - 5 } & $\mathrm{N}$ & 168 & 168 & 168 \\
\hline
\end{tabular}

** La correlación es significativa al nivel 0,01 (bilateral). Fuente: Elaboración propia.

\subsection{Comparación entre grupos}

Diferencia entre géneros: De acuerdo a la aplicación de la prueba T para muestras independientes y la significancia lateral asumiendo varianzas iguales en la comparación, se establece que la significancia bilateral no muestra diferencias entre género y las dimensiones, a excepción de la dimensión Geomática, en la que se presenta un valor menor a 0,05 (Tabla 4). Llaman la atención las dimensiones Afectividad y Significatividad-Comunicabilidad, en las cuales se esperaba diferencias significativas por género, pero que en el caso del muestro no existen.

TABLA 4

Prueba T para muestras independientes (género vs dimensiones)

\begin{tabular}{|l|c|c|c|c|}
\hline & $\begin{array}{c}\text { PrOMEDIO } \\
\text { HOMBres }\end{array}$ & $\begin{array}{c}\text { PROMEDIO } \\
\text { MUjERES }\end{array}$ & $\mathrm{T}$ & $\begin{array}{c}\text { SIG } \\
\text { (BILATERAL) }\end{array}$ \\
\hline Dimensión Geomática & 4,0507 & 3,8694 & 2,241 &, 026 \\
\hline Dimensión Territorialidad & 3,7162 & 3,6025 & 1,301 &, 195 \\
\hline Dimensión Afectividad & 2,7320 & 2,6812 & 0,443 &, 658 \\
\hline $\begin{array}{l}\text { Dimensión Significatividad- } \\
\text { Comunicabilidad }\end{array}$ & 3,1149 & 3,0761 & 0,413 &, 680 \\
\hline
\end{tabular}

Fuente: Elaboración propia.

- Diferencia entre nacionalidades: Para este caso los valores de significancia bilateral de las dimensiones Geomática y Territorialidad son menores a 0,05 (asumiendo varianzas iguales), por lo que hay diferencias significativas entre nacionalidad de los encuestados y su utilización de herramientas geomáticas y la percepción del territorio con dichos programas (Tabla 5). Estos valores se podrían explicar por el acceso a la tecnología que tienen los encuestados, la posibilidad de conectividad y su participación en redes sociales que involucren el dominio espacial dentro de sus datos de divulgación. Para el caso español la penetración de redes sociales y dispositivos superan la media de los países de la OCDE a diferencia de Chile, en que se encuentra en los niveles promedios (IAB Spain, 2013). 
JOSÉ MANUEL MUÑOZ RODRÍGUEZ, JORGE JOO NAGATA Y JOSÉ RAFAEL GARCÍA-BERMEJO GINER HERRAMIENTAS GEOMÁTICAS UTILIZADAS EN EDUCACIÓN: SITUACIÓN ACTUAL..

TABLA 5

Prueba $\mathrm{T}$ para muestras independientes (nacionalidad vs dimensiones)

\begin{tabular}{|l|c|c|c|c|}
\hline & $\begin{array}{c}\text { PROMEDIO } \\
\text { HOMBRES }\end{array}$ & $\begin{array}{c}\text { PROMEDIO } \\
\text { MuJERES }\end{array}$ & T & $\begin{array}{c}\text { SIG } \\
\text { (BILATERAL) }\end{array}$ \\
\hline Dimensión Geomática & 4,0241 & 3,7850 & 2,756 &, 007 \\
\hline Dimensión Territorialidad & 3,7241 & 3,4818 & 2,611 &, 010 \\
\hline Dimensión Afectividad & 2,6766 & 2,7467 &,- 563 &, 574 \\
\hline $\begin{array}{l}\text { Dimensión Significatividad- } \\
\text { Comunicabilidad }\end{array}$ & 3,1389 & 3,0075 & 1,291 &, 198 \\
\hline
\end{tabular}

Fuente: Elaboración propia.

\section{CONCLUSIONES}

Es posible establecer que en el grupo de universitarios consultados la sensación de espacio y sus componentes, con el uso de las herramientas geomáticas, se mantiene en un nivel básico, llegando a una posibilidad inicial de compartir elementos concretos como son la localización, la referencia y los elementos visuales que existen en los territorios que experimentan. Además, como seres sociales, se da la capacidad de comunicar perspectivas y actitudes comunes hacia los lugares, los cuales se traducen en información que sí puede ser compartida mediante los recursos existentes en Internet y en particular con este tipo de programas asociados sobre todo a redes sociales. Sin embargo, los elementos afectivos y emotivos, que son personales e intransferibles y definen a los individuos como únicos, tienen otro tipo de sistema interpretativo y comunicativo, por lo que no pueden ser abordados en la utilización de este tipo de programas. Los simbolismos personales que hemos creado como personas y en los que el territorio es parte fundamental todavía no tendrían un equivalente en el mundo digital y, con ello, en este tipo de herramientas.

En la investigación y en la respectiva muestra se establece que existe un claro conocimiento sobre las herramientas TIC geomáticas, aunque inicial y elemental, pero que va desarrollándose a la par con la tecnología que se muestra en el contexto de la Web 2.0. La relativa realidad que ofrecen estas herramientas, el desarrollo de sus interfaces y la exposición gráfica de los datos territoriales permiten que los jóvenes encuestados asuman la información entregada como parte de su vida cotidiana, y por lo tanto de su entorno, transformando estos datos digitales en una especie de "realidad inicial virtual". Lo anterior se complementa por las limitantes que existen en el espacio real, debido a su estructura tangible y concreta, que se expresa en costos de desplazamiento, tiempo y accesibilidad. Se ha determinado que en la utilización de estos programas no hay un único uso, que se debería traducir exclusivamente en la visualización de imágenes, datos o simples representaciones del espacio. También existen aplicaciones en donde la información se transforma en posibles reflejos de una realidad física territorial, una forma de 
JOSÉ MANUEL MUÑOZ RODRÍGUEZ, JORGE JOO NAGATA Y JOSÉ RAFAEL GARCÍA-BERMEJO GINER HERRAMIENTAS GEOMÁTICAS UTILIZADAS EN EDUCACIÓN: SITUACIÓN ACTUAL...

acceder inicialmente a la información sobre los lugares que se consultan y no se conocen en la realidad. De manera paralela, cerca del 68\% de los estudiantes consultados cree que existen potencialidades educativas en torno a estas herramientas, lo que es significativo considerando que su formación está relacionada con temáticas territoriales y sociales.

En torno a la hipótesis de trabajo, esta quedaría rechazada ya que existe un grado de correlación, entre el significado que los encuestados le otorgan a los territorios y la forma en que estas herramientas presentan dicha información. En estos programas hay un desarrollo inicial de acciones, procesos e interpretaciones, lo mismo que ocurre en los territorios reales. Esto no quiere decir que los individuos encuestados representen y entiendan, de manera análoga, los territorios reales y los datos modelados en las herramientas geomáticas.

Como otras herramientas informáticas utilizadas en educación, creemos que las herramientas TIC geomáticas requieren el esclarecimiento de competencias y habilidades en la enseñanza y evaluación de los estudiantes, involucrando cambios en el diseño de estrategias, metodologías de enseñanza y herramientas de software apropiadas para los diferentes contextos educativos existentes con el fin de lograr procesos más eficaces en la enseñanza de los territorios.

\section{REFERENCIAS BIBLIOGRÁFICAS}

Artvinli, E. (2010). The contribution of geographic information systems (GIS) to geography education and secondary school students' attitudes related to GIS. Educational Sciences: Theory and Practice, 10 (3), 1277-1292.

Bosque, I. (2012). Los sistemas de información geográfica y la investigación en ciencias humanas y sociales. Madrid: Confederación Española de Centros de Estudios Locales.

Burrough, P. A. y McDonnell, R. (1998). Principles of Geographical Information Systems (vol. 3). Oxford: Oxford University Press.

Buzai, G. D. (1999). Geografía global: el paradigma geotecnológico y el espacio interdisciplinario en la interpretación del mundo del siglo xxI. Buenos Aires: Lugar.

Calvo, M. (2011). Geo-conceptualización y modelado del espacio geográfico. Madrid: Editorial Académica Española. Recuperado a partir de https:/www.eae-publishing.com/ catalog/details/store/es/book/978-3-8465-6367-0/geo-conceptualizaci\%C3\%B3n-y-modelado-del-espacio-geogr\%C3\%A1fico.

Capel, H. (2009). La enseñanza digital, los campus virtuales y la geografía. Geocrítica. Recuperado el 23 de enero de 2013, a partir de http://www.ub.edu/geocrit/aracne/ aracne-125.htm.

Capel, H. (2012). Filosofía y ciencia en la geografía contemporánea: una introducción a la geografía. Barcelona: Ediciones del Serbal.

Cerda, D. (2008). Tierra, sentido y territorio: La ecuación geosemática. Revista Aainteligencia. Recuperado el 23 de enero de 2013, a partir de http://www.aainteligencia. $\mathrm{cl} / \mathrm{p}=133$.

Comes, P. (2002). Geografía escolar y tecnologías de la información y el conocimiento (TIC). Didáctica de las Ciencias Sociales, Geografía e Historia, 32, 50-61.

Contreras, M. (2013). El mercado del PC se desploma. FayerWayer. Recuperado a partir de http://www.fayerwayer.com/2013/04/mercado-pc-desploma/. 
JOSÉ MANUEL MUÑOZ RODRÍGUEZ, JORGE JOO NAGATA Y JOSÉ RAFAEL GARCÍA-BERMEJO GINER HERRAMIENTAS GEOMÁTICAS UTILIZADAS EN EDUCACIÓN: SITUACIÓN ACTUAL...

Cowen, D. J. (1988). GIS versus CAD versus DBMS: What are the differences? Photogrammetric Engineering and Remote Sensing, 54, 15-19.

Dangermond, J. (2004). Keynote address to ESRI User Conference. En ESRI User Conference. Presentado en San Diego. Recuperado a partir de http://www.esri.com.

Departamento de Historia y Geografía y umCE (2009). Informe de Autoevaluación 2008. Santiago, Chile: Universidad Metropolitana de Ciencias de la Educación.

Enlaces (2011). Competencias y estándares TIC para la profesión docente (p. 98). Santiago de Chile: Ministerio de Educación, Chile. Recuperado a partir de http://www.enlaces. $\mathrm{cl} /$ libros/docentes/index.html.

Freyman, R. (2012). Ciudad y ciudadanos. Etcétera. Recuperado el 22 de enero de 2013, a partir de http://www.etcetera.com.mx/articulo.php?articulo=15138.

García del Dujo, Á. (2009). Análisis del espacio en los entornos virtuales de formación. Teoría de la Educación, 21, 103-128.

García del Dujo, Á. y Muñoz, J. M. (2007). Pedagogía de los espacios: análisis terminológico y construcción conceptual. Ethos Educativo, 39 (2), 17-28.

Garrido, M. (2005). El Espacio por aprender, el mismo que enseñar: las urgencias de la educación geográfica. Cadernos CEDES. Campinas, 25 (66), 137-163.

Goodchild, J. (2007). Citizens as sensors: the world of volunteered geography. GeoJournal, 69, 211-221. http://dx.doi.org/10.1007/s10708-007-9111-y

Google (2013). Google Earth. Recuperado el 2 de abril de 2013, a partir de http://www. google.es/intl/es/earth/index.html.

Hernández, R.; Fernández, C. y Baptista, P. (2010). Metodología de la investigación (5. ${ }^{\text {e ed. }) .}$ México: McGraw Hill.

IAB Spain (2013). IV Estudio anual de redes sociales. Interactive Advertising Bureau Spain. Recuperado a partir de http://www.iabspain.net/wp-content/plugins/download-monitor/download.php?id=114.

IDEE (2010). Análisis comparativo de Servidores de Mapas. Blog IDEE. Análisis comparativo de servidores de mapas. Recuperado a partir de http://blog-idee.blogspot.com. es/2010/08/analisis-comparativo-de-servidores-de.html.

Jenner, P. (2006). Engaging students through the use of GIS at Pimlico State High School. International Research in Geographical and Environmental Education, 15 (3), 278-282. http://dx.doi.org/10.2167/irgee196g.0

Lloret, J. R.; Omtzigt, N.; Koomen, E. y De Blois, F. S. (2008). 3D visualisations in simulations of future land use: exploring the possibilities of new, standard visualisation tools. International Journal of Digital Earth, 1 (1), 148-154.

http://dx.doi.org/10.1080/17538940701782718

López, G. B. (2012). Geolocalización y Redes Sociales. Madrid: Bubok.

Martín, A. V.; Muñoz, J. M.; García del Dujo, Á. y Sánchez, M. C. (2011). Notas para una interpretación educativa del espacio-tiempo social en la Red. Pedagogía Social. Revista Interuniversitaria, 18, 13-30.

Mizala, A. (2011). Determinantes de la elección y deserción en la carrera de Pedagogía (Fonide n. ${ }^{\circ}$ F511059) (p. 92). Santiago, Chile: Centro de Investigación Avanzada en Educación, Universidad de Chile. Recuperado a partir de http://www.comunidadescolar.cl/ documentacion/FONIDE/Informe\%20Final-Alejandra\%20Mizala-UdeChile-F511059.pdf. 
JOSÉ MANUEL MUÑOZ RODRÍGUEZ, JORGE JOO NAGATA Y JOSÉ RAFAEL GARCÍA-BERMEJO GINER HERRAMIENTAS GEOMÁTICAS UTILIZADAS EN EDUCACIÓN: SITUACIÓN ACTUAL...

Muñoz, J. M. (2013). Programa curso Pedagogía Antropológica. Universidad de Salamanca. Recuperado a partir de https://moodle.usal.es/mod/resource/view. php?inpopup=true\&id=397326.

Pérez, E. (2003). La situación de las mujeres en el sistema educativo de ciencia y tecnología en España y su contexto internacional. (Programa de análisis y estudios de acciones destinadas a la mejora de la calidad de la enseñanza superior y de actividades del profesorado. No. S2/EA2003-031) (p. 2007). Madrid: Unesco. Recuperado a partir de http://www.ohchr.org/Documents/Issues/CulturalRights/ConsultationEnjoyBenefits/ UNESCOLASITUACIaNDELASMUJERESENELSISTEMA.pdf.

Prensky, M. (2001). Digital natives, digital inmigrants. On the Horizon, 9 (5), 1-6. http://dx.doi.org/10.1108/10748120110424843 http://dx.doi.org/10.1108/10748120110424816

Royo, J. (2004). Diseño digital. Editorial Paidós.

Santisteban, A. y Pagès, J. (2011). Didáctica del Conocimiento Social y Cultural en la Educación Primaria: Ciencias Sociales para comprender, pensar y actuar. Madrid: Síntesis.

Sengupta, S. (2007). Geographical Information System Concepts And Business Opportunities. Concept Publishing Company.

Tuan, Y.-F. (2007). Topofilia: un estudio de las percepciones, actitudes y valores sobre el entorno. Barcelona: Melusina.

VTR, Adimark y Educar Chile (2008). Índice de Generación Digital 2004-2008. Recuperado a partir de http://www.educarchile.cl/UserFiles/P0001/File/CR_Articulos/IGD_2008.pdf.

\section{ANEXO 1}

\section{CUESTIONARIO SOBRE LA PERCEPCIÓN DEL ESPACIO EN LA VIRTUALIDAD}

\section{Estimado estudiante:}

En el marco de la investigación Herramientas Geomáticas y Educación: situación, integración y percepción, solicitamos a usted que conteste esta encuesta que tiene como propósito recabar información sobre la percepción que tiene sobre el uso de las herramientas digitales en la visualización y entendimiento del espacio. De esta manera, se pretende generar una primera aproximación sobre estas herramientas y su posible uso en ámbitos como en la Educación.

Por este motivo, le estaríamos muy agradecidos si pudiera dedicar unos minutos de su tiempo y responder a las siguientes cuestiones, rodeando o tachando (X) la modalidad de respuesta que mejor se ajuste a su opinión, respecto a la cuestión planteada en cada caso.

ES MUY IMPORTANTE que tenga presente que las cuestiones se refieren a SU CASO CONCRETO Y PARTICULAR. La duración estimada en la implementación del cuestionario es de 8 a 10 minutos.

Gracias por su ayuda 
54 JOSÉ MANUEL MUÑOZ RODRÍGUEZ, JORGE JOO NAGATA Y JOSÉ RAFAEL GARCíA-BERMEJO GINER HERRAMIENTAS GEOMÁTICAS UTILIZADAS EN EDUCACIÓN: SITUACIÓN ACTUAL...

\section{INFORMACIÓN GENERAL}

1. Edad:

2. Género: Masculino $\square$ Femenino $\square$

3. Grado:

4. Ciudad donde vive:

\section{INFORMACIÓN EN USO DE TIC}

5. ¿Cuánto tiempo dedica al uso del ordenador a la semana?

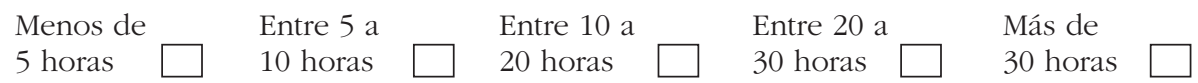

6. ¿Qué dispositivos utiliza habitualmente?

Ordenador de mesa $\square$ Portátil $\square$ Móvil $\square \quad$ Tableta $\square$

7. Alguno de los dispositivos cuenta con GPS o algún otro programa de localización (Google Maps, Bing, Foursquare, etc.)

No $\square$ Sí $\square$ Si la respuesta es positiva ¿đe qué tipo es?

Google map/ $\square$ Bing maps $\square \quad$ Google $\square$ Foursquare $\square$ Openstreetmap $\square$

Google Earth Streetview

$$
\text { Mapred } \square \quad \text { Waze } \square
$$

Otros:

8. Según su percepción: ¿̇en qué nivel se categoriza en el uso de TIC?

Usuario con conocimientos avanzado

\section{Usuario con conocimientos} medio

\section{Usuario con conocimientos} básicos

\section{USO DE HERRAMIENTAS INFORMÁTICAS SOBRE EL TERRITORIO}

9. ¿Qué herramientas de Internet sobre el territorio conoce?

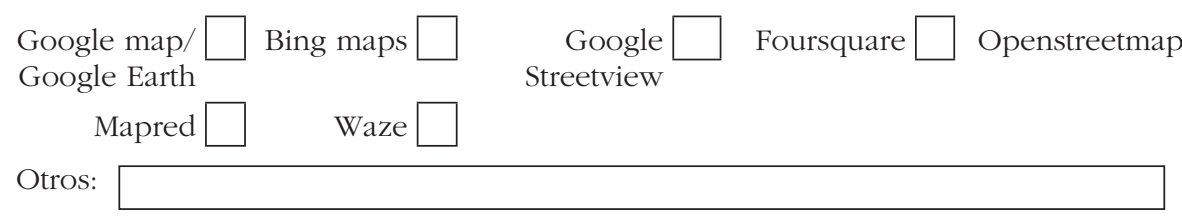

10. ¿Cuál es el nivel de manejo de estas herramientas?
Avanzado
Medio
Básico
Nulo 
En una escala del 1 al 5 siendo el valor 1 "En total desacuerdo" y 5 "muy de acuerdo", responda las siguientes preguntas:

11.- Para buscar una dirección o localización: busco, selecciono y proceso información a través del uso de herramientas Tic.

12.- Si necesito información sobre algún lugar que no conozco, utilizo este tipo de herramientas que hay Internet.

13.- Utilizar este tipo de herramientas que virtualizan el espacio es difícil y muy complejo.

14.- Se requiere tener un conocimiento previo para la adecuada utilización de estas herramientas.

15.- En las redes sociales (Facebook, Twitter, Tuenti, etc.) trato de no mostrar mi localización a mis contactos.

16.- Comprendo adecuadamente bien toda la información que me dan estos programas (localización absoluta, momento, escala, distancia, etc.).

17.- No comprendo cómo se genera toda la información que utilizan estas herramientas.

18.- Generar información del espacio para estas herramientas es fácil y práctico.

19.- Estas herramientas me ayudan a profundizar el conocimiento sobre los lugares que consulto.

20.- El usar programas que visualicen y representen los espacios me es desagradable y complicado.

21.- Estos programas no responden a las necesidades de información que necesito.

22.- Me encuentro bien preparado para utilizar estas herramientas sobre los espacios.

23.- Estas herramientas no representan adecuadamente la realidad espacial (territorial).

24.- La amplitud y tamaño de los lugares son fielmente representados con estas herramientas.

25.- Utilizar estas herramientas es parte de mi necesidad informativa.

26.- Estas herramientas me muestran características de los espacios que no soy capaz de ver.

27.- Utilizando estos programas me siento como si estuviera en el lugar consultado.

28.- Estos programas son fríos, impersonales y no representan mi sentimiento hacia los lugares que consulto.

29.- Mi vida funciona normalmente sin la necesidad de utilizar estos programas.

\begin{tabular}{|c|c|c|c|}
\hline & 2 & 3 & 4 \\
\hline 1 & 2 & 3 & 4 \\
\hline 1 & 2 & 3 & 4 \\
\hline 1 & 2 & 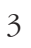 & 4 \\
\hline 1 & 2 & 3 & 4 \\
\hline 1 & 2 & 3 & 4 \\
\hline 1 & 2 & 3 & 4 \\
\hline 1 & 2 & 3 & 4 \\
\hline 1 & 2 & 3 & 4 \\
\hline 1 & 2 & 3 & 4 \\
\hline 1 & 2 & 3 & 4 \\
\hline 1 & 2 & 3 & 4 \\
\hline 1 & 2 & 3 & 4 \\
\hline 1 & 2 & 3 & 4 \\
\hline 1 & 2 & 3 & 4 \\
\hline 1 & 2 & 3 & 4 \\
\hline 1 & 2 & 3 & 4 \\
\hline 1 & 2 & 3 & 4 \\
\hline 1 & 2 & 3 & 4 \\
\hline
\end{tabular}


56 JOSÉ MANUEL MUÑOZ RODRÍGUEZ, JORGE JOO NAGATA Y JOSÉ RAFAEL GARCÍA-BERMEJO GINER HERRAMIENTAS GEOMÁTICAS UTILIZADAS EN EDUCACIÓN: SITUACIÓN ACTUAL...

30.- Estas herramientas sobre el espacio son parte de mi vida cotidiana.

31.- Con mis amistades compartimos las mismas herramientas y experiencias sobre el espacio.

32.- Ver los espacios de manera virtual me genera la misma percepción que si estuviera de manera presencial.

$\begin{array}{lllll}1 & 2 & 3 & 4 & 5 \\ 1 & 2 & 3 & 4 & 5 \\ 1 & 2 & 3 & 4 & 5 \\ 1 & 2 & 3 & 4 & 5 \\ 1 & 2 & 3 & 4 & 5 \\ 1 & 2 & 3 & 4 & 5 \\ 1 & 2 & 3 & 4 & 5 \\ 1 & 2 & 3 & 4 & 5 \\ 1 & 2 & 3 & 4 & 5 \\ 1 & 2 & 3 & 4 & 5 \\ 1 & 2 & 3 & 4 & 5\end{array}$

33.- Puedo compartir lugares de manera virtual a través de estas herramientas.

34.- Cada vez que utilizo estos programas puedo aprender de lugares y situaciones nuevas.

35.- Estas herramientas no facilitan el intercambio de ideas, alegrías, experiencias, etc., que se viven en los lugares reales.

36.- Puedo visualizar y comprender más información que la simplemente mostrada por estas herramientas sobre el espacio.

37.- El utilizar estas herramientas ayuda a intercambiar ideas e información sobre el lugar que consulto.

38.- Estas herramientas están hechas para que todo tipo de público pueda comprender sobre el espacio (o territorio).

39.- Creo que los estudiantes no podrían aprender del espacio (o territorio) con el uso de estas herramientas.

0.- Estas herramientas reemplazan a la realidad de los espacios.

OBSERVACIONES (voluntario): 